\title{
Magnetic Glyco-nanoparticles: A Unique Tool for Rapid Pathogen Detection, De- contamination and Strain Differentiation
}

\section{Supporting Information}

Kheireddine El-Boubbou, ${ }^{a}$ Cyndee Gruden, ${ }^{\mathrm{b}}$ Xuefei Huang ${ }^{\mathrm{a} *}$

${ }^{a}$ Department of Chemistry, The University of Toledo, 2801 W. Bancroft Street, MS 602, Toledo, $\mathrm{OH} 43606$

${ }^{\mathrm{b}}$ Department of Civil Engineering, The University of Toledo, $2801 \mathrm{~W}$. Bancroft Street, MS 307, Toledo, OH 43606

xuefei.huang@utoledo.edu

\section{Table of contents:}

\section{Contents}

1- $\quad$ Materials and Instrumentation $\quad$ S2

2- $\quad$ Syntheses of magnetic glyco-nanoparticles (MGNP) S3

a- $\quad$ Synthesis of carbohydrate building blocks (Man and Gal) S3

b- $\quad$ Synthesis of $\mathrm{Fe}_{3} \mathrm{O}_{4}$ nanoparticles and immobilization $\quad \mathrm{S} 6$

3- Characterization of MGNPs $\quad$ S8

4- Con A studies $\quad$ S12

5- $\quad$ E. coli detection $\quad$ S14

$\begin{array}{lll}\text { 6- } & \text { Selected NMR spectra } & \text { S17 }\end{array}$

7- References $\quad$ S26 


\section{1- Materials and Instrumentation:}

Materials: Unless otherwise indicated, all starting materials, reagents and solvents were obtained from commercial suppliers and used as supplied without further purification. Fluorescein concanavalin A (Con A-FITC) was purchased from Molecular Probes. E. coli ORN178 and ORN208 strains were kindly donated by Prof. Orndorff (North Carolina State University). All oxygen and moisture sensitive reactions were carried under nitrogen. Air sensitive solvents were transferred via syringe. Column chromatography was performed employing 230-400 mesh silica gels. Thin-layer chromatography (TLC) was performed using glass plates pre-coated to a depth of $0.25 \mathrm{~mm}$ with $230-400$ mesh silica gel impregnated with a fluorescent indicator $(254 \mathrm{~nm})$. All compounds were visualized by the use of UV light or a yellow stain containing $\mathrm{Ce}\left(\mathrm{NH}_{4}\right)_{2}\left(\mathrm{NO}_{3}\right)_{6}(0.5 \mathrm{~g})$ and $\left(\mathrm{NH}_{4}\right)_{6} \mathrm{Mo}_{7} \mathrm{O}_{24} .4 \mathrm{H}_{2} \mathrm{O}(24.0 \mathrm{~g})$ in $6 \% \mathrm{H}_{2} \mathrm{SO}_{4}(500 \mathrm{~mL})$. Degassed and double deionized water (DDW) was used in all the biological assays.

Instrumentation: NMR spectra were recorded on a Varian VXRS-400 or Inova-600 instruments and were referenced using $\mathrm{Me}_{4} \mathrm{Si}(0 \mathrm{ppm})$, residual $\mathrm{CHCl}_{3}\left(\delta{ }^{1} \mathrm{H}-\mathrm{NMR} 7.26\right.$ ppm) $\mathrm{CDCl}_{3}\left(\delta{ }^{13} \mathrm{C}-\mathrm{NMR} 77.0 \mathrm{ppm}\right)$, residual $\mathrm{CHD}_{2} \mathrm{OD}\left(\delta{ }^{1} \mathrm{H}-\mathrm{NMR} 5.32 \mathrm{ppm}\right), \mathrm{CD}_{3} \mathrm{OD}$ $\left(\delta{ }^{13} \mathrm{C}\right.$-NMR $\left.49.0 \mathrm{ppm}\right)$. Assignments of proton and carbon signals were carried out with the aid of gCOSY experiments. ESI mass spectra were recorded on ESQUIRE LC-MS operated in positive ion mode. High-resolution mass spectra were recorded on a Micromass electrospray Tof ${ }^{\mathrm{TM}}$ II (Micromass, Wythenshawe, UK) mass spectrometer equipped with an orthogonal electrospray source (Z-spray) operated in positive ion mode, which is located at the Mass Spectrometry and Proteomics Facility, the Ohio State University. X ray diffraction spectrum (XRD) was recorded using Rigaku Ultima III multipurpose X-ray diffraction system. FTIR spectra $\left(400-4000 \mathrm{~cm}^{-1}\right)$ were recorded as $\mathrm{KBr}$ pellet forms using FTIR Perkin Elmer Spectrum GX with ATR capabilities. Fluorescence emission spectra were recorded on an AMINCO BOWMAN II Luminescence spectrometer provided with a continuous $(\mathrm{CW})$ high power Xe lamp as the excitation source and an excitation wavelength of $492 \mathrm{~nm}$ and spectra-recording at 500$650 \mathrm{~nm}$. Thermogravimetric analysis (TGA) was carried out on an SDT 2960 Simultaneous DTA-TGA equipment and the samples were burned in air at a constant heating rate of $10{ }^{\circ} \mathrm{C} / \mathrm{min}$ from 50 to $1000{ }^{\circ} \mathrm{C}$. Transmission electron microscopy (TEM) images were obtained using a Philips CM10 Mawah-NJ software Image Pro Plus 6.0, operating at $100 \mathrm{kV}$. Bacterium enumeration was carried out using an epifluorescent microscope (Olympus BX-51) with a 50-W Osram UV mercury lamp. 


\section{2- Syntheses of magnetic glyco-nanoparticles (MGNP)}

a- Synthesis of sugar building blocks (mannose and galactose)

Synthesis of mannose amido-acid (M5).

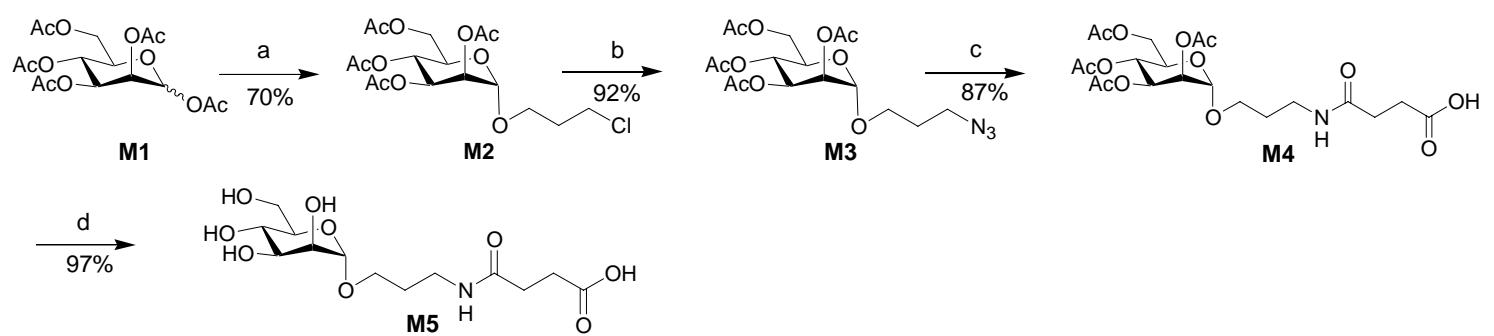

Reagents and conditions: a) 3-chloro-1-propanol, $\mathrm{BF}_{3} \cdot \mathrm{Et}_{2} \mathrm{O}, \mathrm{DCM}$; b) $\mathrm{NaN}_{3}, \mathrm{DMF}, 80{ }^{0} \mathrm{C}$; c) succinic anhydride, $\mathrm{H}_{2} / \mathrm{Pd}-\mathrm{C}, \mathrm{THF}$, 3h; d) $\mathrm{MeONa}, \mathrm{MeOH}$

3-Azidopropyl 2,3,4,6-tetra-O-acetyl-a-D-mannopyranoside (M3). M3 was prepared as previously described starting from pentaacetyl mannose M1.$^{1-3}$ Comparison of NMR spectra with those reported ${ }^{1-3}$ confirms its structure.

$\boldsymbol{O}$-Acetyl protected mannose amido-acid (M4). A solution of M3 (0.650 g, $1.51 \mathrm{mmol})$, succinic anhydride $(0.230 \mathrm{~g}, 2.30 \mathrm{mmol})$ and $10 \% \mathrm{Pd} / \mathrm{C}(0.166 \mathrm{~g})$ in dry THF $(20 \mathrm{~mL})$ was stirred at room temperature under $\mathrm{H}_{2}$. After 3 hours, TLC (EtOAc-hexanes, 1:1) showed complete conversion of starting material $\left(\mathrm{R}_{f}=0.5\right)$ to a major product $\left(\mathrm{R}_{f}=0.0\right)$. The reaction mixture was then filtered off through Celite and concentrated. The residue was purified by column chromatography starting from EtOAc-hexanes 1:1 increasing to MeOH-DCM, 1:10 to afford the product M4 as a sticky white solid (0.67 g, $88 \%$ yield). ${ }^{1} \mathrm{H}$ NMR $\left(\mathrm{CDCl}_{3}, 600 \mathrm{MHz}\right): \delta_{\mathrm{H}} 1.78-1.85\left(\mathrm{~m}, 2 \mathrm{H}, \mathrm{OCH}_{2} \mathrm{CH}_{2} \mathrm{CH}_{2} \mathrm{NH}\right), 1.97(\mathrm{~s}, 3 \mathrm{H}$, OAc), 2.03 (s, 3H, OAc), 2.08 (s, 3H, OAc), 2.13 (s, 3H, OAc), 2.50 (t, J=6.3 Hz, 2H, $\left.\mathrm{COCH}_{2} \mathrm{CH}_{2} \mathrm{COOH}\right), 2.64\left(\mathrm{t}, J=6.0 \mathrm{~Hz}, 2 \mathrm{H}, \mathrm{COCH}_{2} \mathrm{CH}_{2} \mathrm{COOH}\right), 3.35$ (t, $J=6.0 \mathrm{~Hz}, 2 \mathrm{H}$, $\mathrm{OCH}_{2} \mathrm{CH}_{2} \mathrm{CH}_{2} \mathrm{NH}$ ), 3.47-3.50 (m, $\left.1 \mathrm{H}, \mathrm{OCHHCH}_{2}\right), 3.74-3.78\left(\mathrm{~m}, 1 \mathrm{H}, \mathrm{OCHHCH}_{2}\right), 3.95-$ 3.97 (m, 1H, H-5), 4.11 (dd, $J=2.4,12.0 \mathrm{~Hz}, 1 \mathrm{H}, \mathrm{H}-6 \mathrm{a}), 4.24$ (dd, $J=4.8,12.0 \mathrm{~Hz}, 1 \mathrm{H}$, H-6b), 4.79 (d, $J=1.2 \mathrm{~Hz}, 1 \mathrm{H}, \mathrm{H}-1), 5.21$ (dd, $J=1.2,2.4 \mathrm{~Hz}, 1 \mathrm{H}, \mathrm{H}-2), 5.25-5.27$ (m, $2 \mathrm{H}, \mathrm{H}-3, \mathrm{H}-4), 6.42$ (bs, $1 \mathrm{H}, \mathrm{NH}) .{ }^{13} \mathrm{C} \mathrm{NMR}\left(\mathrm{CDCl}_{3}, 100 \mathrm{MHz}\right): \delta_{\mathrm{C}} 20.9,21.0,21.1(4 \mathrm{C}$, $\left.\mathrm{CH}_{3}\right), 29.2\left(1 \mathrm{C}, \mathrm{CH}_{2} \mathrm{CH}_{2} \mathrm{NH}\right), 30.1\left(1 \mathrm{C}, \mathrm{COCH}_{2}\right), 31.0(1 \mathrm{C}, \mathrm{CH} 2 \mathrm{COOH}), 37.6(1 \mathrm{C}$, $\left.\mathrm{CH}_{2} \mathrm{CH}_{2} \mathrm{NH}\right), 62.8\left(1 \mathrm{C}, \mathrm{CH}_{2} \mathrm{OAc}\right), 66.3(1 \mathrm{C}, \mathrm{CH}), 66.8(1 \mathrm{C}, \mathrm{CH}), 68.7\left(1 \mathrm{C}, \mathrm{CH}_{2} \mathrm{O}\right), 69.4$ $(1 \mathrm{C}, \mathrm{CH}), 69.7(1 \mathrm{C}, \mathrm{CH}), 97.8\left(1 \mathrm{C}, \mathrm{C}_{\text {anomeric }}\right), 170.0\left(1 \mathrm{C}, \mathrm{CH}_{3} \mathrm{C}(\mathrm{O}) \mathrm{O}\right), 170.4(1 \mathrm{C}$, $\left.\mathrm{CH}_{3} \mathrm{C}(\mathrm{O}) \mathrm{O}\right), 170.5\left(1 \mathrm{C}, \mathrm{CH}_{3} \mathrm{C}(\mathrm{O}) \mathrm{O}\right), 171.2$ (1C, $\left.\mathrm{CH}_{3} \mathrm{C}(\mathrm{O}) \mathrm{O}\right), 172.9$ (1C), 175.9 (1C). ESI-MS $m / z$ calcd. for $\mathrm{C}_{21} \mathrm{H}_{31} \mathrm{NNaO}_{13}[\mathrm{M}+\mathrm{Na}]^{+}:$528.5; found: 528.4 .

Mannose amido-acid (M5). A freshly prepared solution of $\mathrm{NaOMe}-\mathrm{MeOH}(0.35 \mathrm{~mL}, 1$ M) was added to a solution of M4 $(0.350 \mathrm{~g}, 0.692 \mathrm{mmol})$ in dry methanol $(8 \mathrm{~mL})$ at room temperature under nitrogen. The mixture was stirred for 5 hours, neutralized with Amberlite IR-120 $\left(\mathrm{H}^{+}\right)$ion-exchange resin, filtered, and concentrated. Flash column chromatography (MeOH-DCM, 1:1) of the residue afforded $\mathbf{M 5}$ as a gel like white solid in $97 \%$ yield $(0.23 \mathrm{~g}) .{ }^{1} \mathrm{H}$ NMR $\left(\mathrm{CD}_{3} \mathrm{OD}, 600 \mathrm{MHz}\right): \delta_{\mathrm{H}} 1.76-1.80 \quad(\mathrm{~m}, 2 \mathrm{H}$, $\left.\mathrm{OCH}_{2} \mathrm{CH}_{2} \mathrm{CH}_{2} \mathrm{NH}\right), 2.45$ (t, $\left.J=6.9 \mathrm{~Hz}, 2 \mathrm{H}, \mathrm{COCH}_{2} \mathrm{CH}_{2} \mathrm{COOH}\right), 2.56(\mathrm{t}, J=6.9 \mathrm{~Hz}, 2 \mathrm{H}$, 
$\left.\mathrm{COCH}_{2} \mathrm{CH}_{2} \mathrm{COOH}\right), \quad 3.23-3.29\left(\mathrm{~m}, \quad 2 \mathrm{H}, \quad \mathrm{OCH}_{2} \mathrm{CH}_{2} \mathrm{CH}_{2} \mathrm{NH}\right), \quad 3.43-3.47 \quad(\mathrm{~m}, \quad 1 \mathrm{H}$, $\left.\mathrm{OCHHCH}_{2}\right), 3.50-3.54(\mathrm{~m}, 1 \mathrm{H}, \mathrm{H}-5), 3.58$ (t, $\left.J=9.6 \mathrm{~Hz}, 1 \mathrm{H}, \mathrm{H}-4\right), 3.68-3.71(\mathrm{~m}, 2 \mathrm{H}, \mathrm{H}-$ 3, H-6a), 3.76-3.80 (m, 2H, H-2, $\mathrm{OCHHCH}_{2}$ ), 3.84 (dd, J=2.1, $\left.11.7 \mathrm{~Hz}, 1 \mathrm{H}, \mathrm{H}-6 \mathrm{~b}\right), 4.74$ $(\mathrm{d}, J=1.2 \mathrm{~Hz}, 1 \mathrm{H}, \mathrm{H}-1) .{ }^{13} \mathrm{C} \mathrm{NMR}\left(\mathrm{CD}_{3} \mathrm{OD}, 100 \mathrm{MHz}\right): \delta_{\mathrm{C}} 29.1\left(1 \mathrm{C}, \mathrm{CH}_{2} \mathrm{CH}_{2} \mathrm{CH}_{2} \mathrm{NH}\right)$, $31.0\left(1 \mathrm{C}, \mathrm{COCH}_{2} \mathrm{CH}_{2} \mathrm{COOH}\right), 31.4\left(1 \mathrm{C}, \mathrm{COCH}_{2} \mathrm{CH}_{2} \mathrm{COOH}\right), 36.4\left(1 \mathrm{C}, \mathrm{CH}_{2} \mathrm{CH}_{2} \mathrm{NH}\right)$, $61.7\left(1 \mathrm{C}, \mathrm{CH}_{2} \mathrm{OH}\right), 64.8\left(1 \mathrm{C}, \mathrm{CH}_{2} \mathrm{CH}_{2} \mathrm{O}\right), 67.5(1 \mathrm{C}, \mathrm{CH}), 71.0\left(1 \mathrm{C}, \mathrm{CH}_{2} \mathrm{O}\right), 71.4(1 \mathrm{C}$, $\mathrm{CH}), 73.5(1 \mathrm{C}, \mathrm{CH}), 100.5$ (1C, $\left.\mathrm{C}_{\text {anomeric }}\right), 174.0$ (1C). HRMS m/z calcd. for $\mathrm{C}_{13} \mathrm{H}_{23} \mathrm{NNaO}_{9}[\mathrm{M}+\mathrm{Na}]^{+}: 360.1271$, found: 360.1273 .

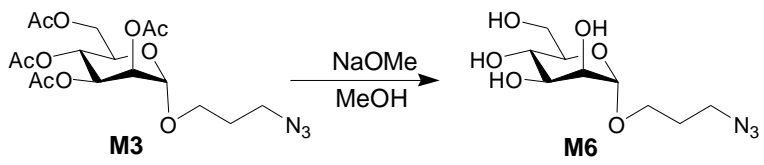

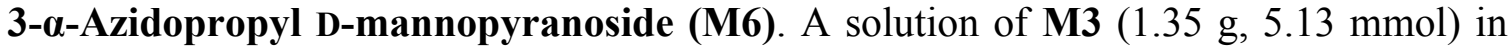
$\mathrm{MeOH}(10 \mathrm{~mL})$ was treated with a solution of sodium $(23 \mathrm{mg})$ in $\mathrm{MeOH}(1 \mathrm{~mL})$. After 1 hour, the solution was acidified with Amberlite IR- $120 \mathrm{H}^{+}$to $\mathrm{pH}$ 6. Evaporation of the solvent under reduced pressure afforded M6 as a white crystalline solid $(0.783 \mathrm{~g}, 95 \%)$. ${ }^{1} \mathrm{H}$ NMR $\left(\mathrm{CD}_{3} \mathrm{OD}, 600 \mathrm{MHz}\right): \delta_{\mathrm{H}} 1.83-1.88\left(\mathrm{~m}, 2 \mathrm{H}, \mathrm{CH}_{2} \mathrm{CH}_{2} \mathrm{~N}_{3}\right) ; 3.41(\mathrm{td}, J=6.8,3.6$ $\left.\mathrm{Hz}, 2 \mathrm{H}, \mathrm{CH}_{2} \mathrm{~N}_{3}\right) ; 3.48-3.53\left(\mathrm{~m}, 2 \mathrm{H}, \mathrm{OCHHCH}_{2}+\mathrm{H}-5\right) ; 3.60$ (t, $\left.J=9.6 \mathrm{~Hz}, 1 \mathrm{H}, \mathrm{H}-4\right)$; 3.67 (dd, $J=3.2,9.2 \mathrm{~Hz}, 1 \mathrm{H}, \mathrm{H}-3) ; 3.71$ (t, $\left.J=6.0 \mathrm{~Hz}, 1 \mathrm{H}, \mathrm{H}^{\prime}-6\right)$; 3.79-3.85 (m, 3H, H-2, H-6", H-7'); 4.74 (d, $J=1.6 \mathrm{~Hz}, 1 \mathrm{H}, \mathrm{H}-1) .{ }^{13} \mathrm{C} \mathrm{NMR}\left(\mathrm{CD}_{3} \mathrm{OD}, 100 \mathrm{MHz}\right): \delta_{\mathrm{C}} 28.8(1 \mathrm{C}$, $\left.\mathrm{CH}_{2} \mathrm{CH}_{2} \mathrm{~N}_{3}\right) ; 56.2\left(1 \mathrm{C}, \mathrm{CH}_{2} \mathrm{CH}_{2} \mathrm{~N}_{3}\right) ; 61.7\left(1 \mathrm{C}, \mathrm{CH}_{2} \mathrm{OH}\right) ; 64.2\left(1 \mathrm{C}, \mathrm{CH}_{2} \mathrm{CH}_{2} \mathrm{O}\right) ; 67.4(1 \mathrm{C}$, $\mathrm{CH}) ; 71.0(1 \mathrm{C}, \mathrm{CH}) ; 71.4(1 \mathrm{C}, \mathrm{CH}) ; 73.6(1 \mathrm{C}, \mathrm{CH}) ; 100.5$ (1C, $\left.\mathrm{C}_{\text {anomeric }}\right)$.

\section{Synthesis of galactose amido-acid (G5).}
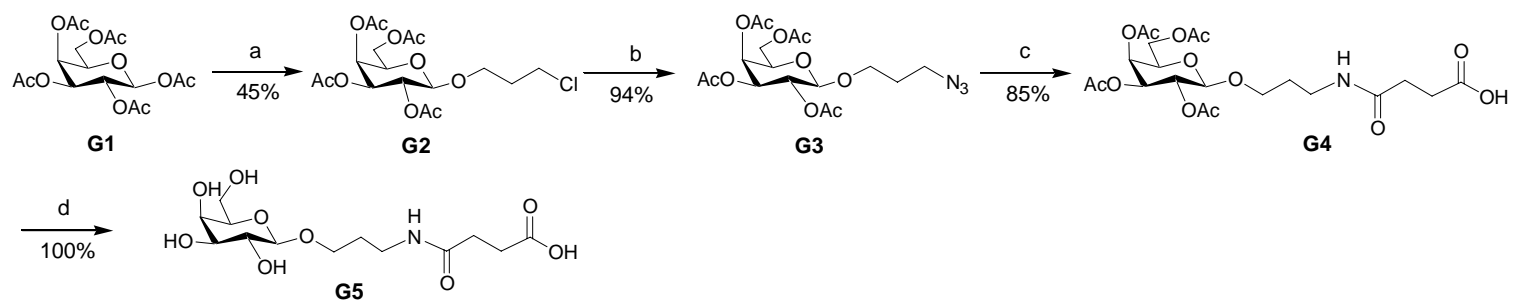

Reagents and conditions: a) 3-chloro-1-propanol, $\mathrm{BF}_{3} . \mathrm{Et}_{2} \mathrm{O}, \mathrm{DCM}$; b) $\mathrm{NaN}_{3}$, DMF, $80{ }^{\circ} \mathrm{C}$; c) succinic anhydride, $\mathrm{H}_{2} / \mathrm{Pd}-\mathrm{C}$, THF, 3h; d) $\mathrm{MeONa}, \mathrm{MeOH}$

3-Azidopropyl 2,3,4,6-tetra- $\boldsymbol{O}$-acetyl- $\boldsymbol{\beta}$-D-galactopyranoside (G3). G3 was prepared analogously as M3 starting from commercially available pentaacetyl galactose $\mathbf{G 1}$. $^{3,4}$ Comparison of NMR spectra with those reported ${ }^{3,4}$ in the literature confirms its structure.

$\boldsymbol{O}$-Acetyl protected galactose amido-acid (G4). A solution of G3 (0.510 g, $1.18 \mathrm{mmol})$, succinic anhydride $(0.180 \mathrm{~g}, 1.80 \mathrm{mmol})$, and $10 \% \mathrm{Pd}-\mathrm{C}(0.130 \mathrm{~g})$ in dry THF $(15 \mathrm{~mL})$ was stirred at room temperature under $\mathrm{H}_{2}$. After 3 hours, TLC (EtOAc-hexanes, 1:1) showed complete conversion of starting material $\left(\mathrm{R}_{f}=0.5\right)$ to a major product $\left(\mathrm{R}_{f}=0.0\right)$. The reaction mixture was then filtered off through Celite and concentrated. The residue was purified by column chromatography starting from 1:1 EtOAc-hexanes to 1:10 MeOH-DCM to afford the product $\mathbf{G} 4$ as a sticky white solid $(0.508 \mathrm{~g}, 85 \%$ yield $) .{ }^{1} \mathrm{H}$ 
NMR $\left(\mathrm{CDCl}_{3}, 600 \mathrm{MHz}\right): \delta_{\mathrm{H}} 1.74-1.86\left(\mathrm{~m}, 2 \mathrm{H}, \mathrm{OCH}_{2} \mathrm{CH}_{2} \mathrm{CH}_{2} \mathrm{NH}\right), 1.99$ (s, 3H, OAc), $2.05(\mathrm{~s}, 3 \mathrm{H}, \mathrm{OAc}), 2.08(\mathrm{~s}, 3 \mathrm{H}, \mathrm{OAc}), 2.17(\mathrm{~s}, 3 \mathrm{H}, \mathrm{OAc}), 2.47-2.70(\mathrm{~m}, 4 \mathrm{H}$, $\mathrm{COCH}_{2} \mathrm{CH}_{2} \mathrm{COOH}$ ), 3.31-3.38 (m, $\left.1 \mathrm{H}, \mathrm{CH}_{2} \mathrm{CHHNH}\right), 3.40-3.46$ (m, $1 \mathrm{H}, \mathrm{CH}_{2} \mathrm{CHHNH}$ ), 3.56-3.61 (m, $\left.1 \mathrm{H}, \mathrm{OCHHCH}_{2}\right), 3.92(\mathrm{td}, J=1.2,10.2 \mathrm{~Hz}, 1 \mathrm{H}, \mathrm{H}-5), 3.98-4.03(\mathrm{~m}, 1 \mathrm{H}$, $\left.\mathrm{OCHHCH}_{2}\right), 4.10-4.15(\mathrm{~m}, 1 \mathrm{H}, \mathrm{H}-6 \mathrm{a}), 4.19-4.24(\mathrm{~m}, 1 \mathrm{H}, \mathrm{H}-6 \mathrm{~b}), 4.44$ (d, J = 7.6 Hz, $1 \mathrm{H}$, H-1), 5.05 (dd, $J=3.6,10.4 \mathrm{~Hz}, 1 \mathrm{H}, \mathrm{H}-3$ ), 5.17 (dd, $J=8.0,10.8 \mathrm{~Hz}, 1 \mathrm{H}, \mathrm{H}-2), 5.40$ (dd, $J=0.8,3.2 \mathrm{~Hz}, 1 \mathrm{H}, \mathrm{H}-4), 6.45(\mathrm{t}, J=5.6 \mathrm{~Hz}, 1 \mathrm{H}, \mathrm{NH}) .{ }^{13} \mathrm{C} \mathrm{NMR}\left(\mathrm{CDCl}_{3}, 100 \mathrm{MHz}\right): \delta_{\mathrm{C}}$ 20.8, 21.9, $21.1\left(4 \mathrm{C}, \mathrm{CH}_{3}\right), 29.1\left(1 \mathrm{C}, \mathrm{CH}_{2} \mathrm{CH}_{2} \mathrm{NH}\right), 30.6\left(1 \mathrm{C}, \mathrm{COCH}_{2}\right), 30.7(1 \mathrm{C}, \mathrm{CH} 2-$ $\mathrm{COOH}), 38.3\left(1 \mathrm{C}, \mathrm{CH}_{2} \mathrm{CH}_{2} \mathrm{NH}\right), 61.5\left(1 \mathrm{C}, \mathrm{CH}_{2} \mathrm{OAc}\right), 67.2(1 \mathrm{C}, \mathrm{CH}), 69.3(1 \mathrm{C}, \mathrm{CH})$, $69.5\left(1 \mathrm{C}, \mathrm{CH}_{2} \mathrm{O}\right), 70.7(1 \mathrm{C}, \mathrm{CH}), 71.0(1 \mathrm{C}, \mathrm{CH}), 101.6\left(1 \mathrm{C}, \mathrm{C}_{\text {anomeric }}\right), 170.3(1 \mathrm{C}$, $\left.\mathrm{CH}_{3} \mathrm{C}(\mathrm{O}) \mathrm{O}\right), 170.46\left(1 \mathrm{C}, \mathrm{CH}_{3} \mathrm{C}(\mathrm{O}) \mathrm{O}\right), 170.54\left(1 \mathrm{C}, \mathrm{CH}_{3} \mathrm{C}(\mathrm{O}) \mathrm{O}\right), 170.8\left(1 \mathrm{C}, \mathrm{CH}_{3} \mathrm{C}(\mathrm{O}) \mathrm{O}\right)$, $173.3(1 \mathrm{C}), 175.3(1 \mathrm{C})$. MS (ESI) $\mathrm{m} / \mathrm{z}$ calcd. for $\mathrm{C}_{21} \mathrm{H}_{31} \mathrm{NNaO}_{13}[\mathrm{M}+\mathrm{Na}]^{+}: 528.5$; found: 528.4 .

Galactose amido-acid (G5). A solution of G4 (0.310 g, $0.613 \mathrm{mmol})$ in $\mathrm{MeOH}(5 \mathrm{~mL})$ was treated with a solution of sodium $(8.60 \mathrm{mg})$ in $\mathrm{MeOH}(0.35 \mathrm{~mL})$ under nitrogen. After $3 \mathrm{~h}$, the solution was acidified with Amberlite IR- $120 \mathrm{H}^{+}$to $\mathrm{pH}=6$. Evaporation of the solvent under reduced pressure afforded $\mathbf{G 5}$ as a white sticky solid in quantitative yield $(0.206 \mathrm{~g})$. ${ }^{1} \mathrm{H}$ NMR $\left(\mathrm{CD}_{3} \mathrm{OD}, 600 \mathrm{MHz}\right): \delta_{\mathrm{H}} 1.74-1.79\left(\mathrm{~m}, 2 \mathrm{H}, \mathrm{OCH}_{2} \mathrm{CH}_{2} \mathrm{CH}_{2} \mathrm{NH}\right)$, $2.44\left(\mathrm{t}, J=6.6 \mathrm{~Hz}, 2 \mathrm{H}, \mathrm{COCH}_{2} \mathrm{CH}_{2} \mathrm{COOH}\right), 2.56\left(\mathrm{t}, J=7.2 \mathrm{~Hz}, 2 \mathrm{H}, \mathrm{COCH}_{2} \mathrm{CH}_{2} \mathrm{COOH}\right.$ ), 3.23-3.27 (m, , $\left.1 \mathrm{H}, \mathrm{OCH}_{2} \mathrm{CH}_{2} \mathrm{CHHNH}\right), 3.31-3.35\left(\mathrm{~m}, 1 \mathrm{H}, \mathrm{OCH}_{2} \mathrm{CH}_{2} \mathrm{CH} H \mathrm{NH}\right), 3.45$ (dd, $J=3.0,9.6 \mathrm{~Hz}, 1 \mathrm{H}$, ) $, 3.49-3.52(\mathrm{~m}, 2 \mathrm{H}, \mathrm{H}-2, \mathrm{H}-5), 3.60(\mathrm{dt}, J=6.0,10.2 \mathrm{~Hz}, 1 \mathrm{H}$, $\left.\mathrm{OCHHCH}_{2}\right), 3.68-3.72(\mathrm{~m}, 1 \mathrm{H}, \mathrm{H}-6 \mathrm{a}), 3.73-3.77(\mathrm{~m}, 1 \mathrm{H}, \mathrm{H}-6 \mathrm{~b}), 3.81(\mathrm{dd}, J=1.2,3.3$ $\mathrm{Hz}, 1 \mathrm{H}, \mathrm{H}-4), 3.92\left(\mathrm{dt}, J=6.0,10.2 \mathrm{~Hz}, 1 \mathrm{H}, \mathrm{OCHHCH}_{2}\right), 4.20$ (d, $\left.J=7.8 \mathrm{~Hz}, 1 \mathrm{H}, \mathrm{H}-1\right)$.

${ }^{13} \mathrm{C}$ NMR $\left(\mathrm{CD}_{3} \mathrm{OD}, 100 \mathrm{MHz}\right): \delta_{\mathrm{C}} 29.1\left(1 \mathrm{C}, \mathrm{CH}_{2} \mathrm{CH}_{2} \mathrm{CH}_{2} \mathrm{NH}\right), 32.6\left(1 \mathrm{C}, \mathrm{COCH}_{2} \mathrm{CH} 2-\right.$ $\mathrm{COOH}), 33.1\left(1 \mathrm{C}, \mathrm{COCH}_{2} \mathrm{CH}_{2} \mathrm{COOH}\right), 36.5\left(1 \mathrm{C}, \mathrm{CH}_{2} \mathrm{CH}_{2} \mathrm{NH}\right), 61.4\left(1 \mathrm{C}, \mathrm{CH}_{2} \mathrm{OH}\right), 67.2$ $\left(1 \mathrm{C}, \mathrm{CH}_{2} \mathrm{CH}_{2} \mathrm{O}\right), 69.3(1 \mathrm{C}, \mathrm{CH}), 71.3\left(1 \mathrm{C}, \mathrm{CH}_{2} \mathrm{O}\right), 73.8(1 \mathrm{C}, \mathrm{CH}), 75.5(1 \mathrm{C}, \mathrm{CH}), 103.8$ $\left(1 \mathrm{C}, \mathrm{C}_{\text {anomeric }}\right), 174.7$ (1C). HRMS $\mathrm{m} / \mathrm{z}$ calcd. for $\mathrm{C}_{13} \mathrm{H}_{23} \mathrm{NO}_{9}[\mathrm{M}+\mathrm{Na}]^{+}: 360.1271$, found: 360.1273 .

\section{Synthesis of Alkyne Linker for Click Chemistry}

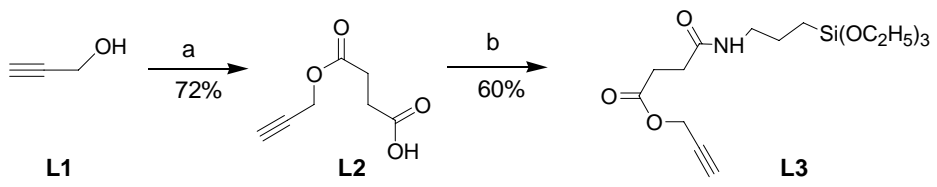

Reagents and conditions: a) succinic anhydride, DMAP, DCM, 6h; d) APTES, EDC, DCM, 12h

Succinic acid prop-2-ynyl ester (L2). To a solution of propargyl alcohol L1 (2.06 g, $36.8 \mathrm{mmol})$ and succinic anhydride $(4.65 \mathrm{~g}, 46.5 \mathrm{mmol})$ in dry DCM $(30 \mathrm{~mL}), 4-$ dimethylaminopyridine (DMAP) $(4.80 \mathrm{~g}, 39.3 \mathrm{mmol})$ was added and the reaction mixture was stirred under nitrogen for 6 hours. After TLC showed complete conversion, the solution was diluted with DCM, acidified with $0.1 \mathrm{M} \mathrm{HCl}$ till $\mathrm{pH}=2$ and then extracted with DCM. The organic layer was then dried and concentrated to afford $4.00 \mathrm{~g}(72 \%)$ of acid $\mathbf{L 2}$ as a white solid. ${ }^{1} \mathrm{H}$ NMR $\left(\mathrm{CDCl}_{3}, 600 \mathrm{MHz}\right): \delta_{\mathrm{H}} 2.47(\mathrm{t}, J=2.4 \mathrm{~Hz}, 1 \mathrm{H}), 2.63-$ $2.70(\mathrm{~m}, 4 \mathrm{H}), 4.68\left(\mathrm{~d}, J=2.4 \mathrm{~Hz}, 2 \mathrm{H}, \mathrm{CH}_{2} \mathrm{O}\right) .{ }^{13} \mathrm{C} \mathrm{NMR}\left(\mathrm{CDCl}_{3}, 100 \mathrm{MHz}\right) \delta_{\mathrm{c}} 28.8,29.0$, 
31.2, 52.6, 75.3, 171.6, 178.3. MS (ESI) $m / z$ calcd. for $\mathrm{C}_{7} \mathrm{H}_{8} \mathrm{NaO}_{4}[\mathrm{M}+\mathrm{Na}]^{+}$: 179.1; found: 179.1 .

Prop-2-ynyl succinate amidopropyl triethoxysilane (L3). To a solution of acid L2 $(0.550 \mathrm{~g}, \quad 3.52 \mathrm{mmol})$ and 1-[3-(dimethylamino)-propyl]-3-ethylcarbodiimide hydrochloride (EDC) (1.00 g, $5.22 \mathrm{mmol})$ in dry DCM $(10 \mathrm{~mL}), \quad 3-$ aminopropyltriethoxysilane (APTES) $(0.942 \mathrm{~g}, 4.25 \mathrm{mmol})$ was added and the reaction mixture was stirred under nitrogen. After 12 hours, the solvent was removed under reduced pressure. The residue was purified by column chromatography from 1:1 EtOAchexanes to 1:10 MeOH-DCM to give $0.75 \mathrm{~g}(60 \%)$ of the desired linker $\mathbf{L 3}$ as a clear white crystalline solid. ${ }^{1} \mathrm{H}$ NMR $\left(\mathrm{CDCl}_{3}, 600 \mathrm{MHz}\right): \delta_{\mathrm{H}} 0.58(\mathrm{t}, J=12.0 \mathrm{~Hz}, 2 \mathrm{H}$, $\left.\mathrm{CH}_{2} \mathrm{CH}_{2} \mathrm{Si}\right), 1.17\left(\mathrm{t}, J=10.8 \mathrm{~Hz}, 9 \mathrm{H},\left(\mathrm{OCH}_{2} \mathrm{CH}_{3}\right)_{3}\right), 1.53-1.60(\mathrm{~m}, 2 \mathrm{H}), 2.43(\mathrm{t}, J=10.8$ $\mathrm{Hz}, 2 \mathrm{H}), 2.45(\mathrm{t}, J=4.2 \mathrm{~Hz}, 1 \mathrm{H}), 2.66(\mathrm{t}, J=10.8 \mathrm{~Hz}, 2 \mathrm{H}), 3.18(\mathrm{q}, J=10.8 \mathrm{~Hz}, 2 \mathrm{H}$, $\left.\mathrm{NHCH}_{2} \mathrm{CH}_{2}\right), 3.76\left(\mathrm{q}, J=10.8 \mathrm{~Hz}, 6 \mathrm{H},\left(\mathrm{OCH}_{2} \mathrm{CH}_{3}\right)_{3}\right), 4.63(\mathrm{~d}, J=3.6 \mathrm{~Hz}, 2 \mathrm{H}$, $\left.\mathrm{CH}_{2} \mathrm{OCO}\right), 6.01(\mathrm{bs}, 1 \mathrm{H}, \mathrm{NH}) .{ }^{13} \mathrm{C} \mathrm{NMR}\left(\mathrm{CDCl}_{3}, 100 \mathrm{MHz}\right) \delta_{\mathrm{c}} 7.9,18.5,23.0,29.5,31.0$, $42.1,52.3,58.6,75.2,77.7,171.1,172.4$. MS (ESI) $\mathrm{m} / \mathrm{z}$ calcd. for $\mathrm{C}_{16} \mathrm{H}_{29} \mathrm{NNaO}_{6} \mathrm{Si}[\mathrm{M}+$ $\mathrm{Na}]^{+}: 382.2$; found: 382.3 .

\section{b- Synthesis of magnetic $\mathrm{Fe}_{3} \mathrm{O}_{4}$ nanoparticles and subsequent immobilization}

\section{Preparation of coated magnetite iron oxide nanoparticles (NP 1):}

Bare $\mathrm{Fe}_{3} \mathrm{O}_{4}$ nanoparticles (NPs) were prepared by slight modification of the coprecipitation method (Scheme S1a) ${ }^{5-7}$ Briefly, $1 \mathrm{M}$ ferric chloride hexahydrate $\left(\mathrm{FeCl}_{3} .6 \mathrm{H}_{2} \mathrm{O}>99 \%\right)$ and $1 \mathrm{M}$ ferrous sulfate heptahydrate $\left(\mathrm{FeSO}_{4} .7 \mathrm{H}_{2} \mathrm{O}>99 \%\right)$ were prepared by dissolving the iron salts in $2 \mathrm{M} \mathrm{HCl}$ solutions, respectively. Then 1 eq. of $\mathrm{Fe}^{3+}$ solution was mixed with 0.5 eq. of $\mathrm{Fe}^{2+}$ solution in a degassed flask. $\mathrm{NH}_{4} \mathrm{OH}(30 \%)$ was added until $\mathrm{pH}$ of 11 was reached. Black precipitates started forming indicating formation of nanoparticles. Adjustment of $\mathrm{pH} \sim 11-12$ is critical to get $10-20 \mathrm{~nm}$ particle size (confirmed by TEM). After vigorous stirring for 30 minutes at room temperature, the resulting black NPs were isolated by applying a permanent external magnet (Lifesep ${ }^{\circledR} 50$ SX magnetic separator), washed 6 times with double deionized water (DDW) and 3 times with ethanol. In an effort to better suit biorecognition purposes, we used polyvinylpyrrolidone (PVP) as the surfactant and tetraethoxysilane (TEOS) as the stable coated silica shell. In a typical experimental procedure, ${ }^{8}$ a solution of PVP $(0.65 \mathrm{~mL}, 25.6 \mathrm{~g} / \mathrm{L})$ was added to the bare $\mathrm{Fe}_{3} \mathrm{O}_{4} \mathrm{NPs}$ suspended in DDW $(150 \mathrm{~mL})$. The mixture was stirred overnight at room temperature. The resulting nanoparticles were then separated, thoroughly washed by water-acetone mixture and re-suspended in 2-propanol: water $(4: 1 \mathrm{v} / \mathrm{v}, 150 \mathrm{~mL})$. $\mathrm{NH}_{4} \mathrm{OH}$ solution $(0.2 \% \mathrm{v} / \mathrm{v}, 0.3 \mathrm{~mL})$ was added followed by dropwise addition of TEOS $(1.5 \mathrm{~mL})$ over 1 hour with continuous stirring. The reaction mixture was stirred overnight, isolated and washed repeatedly with diethyl ether and ethanol leading to silica coated NP $1 .{ }^{9}$

\section{Preparation of Man-MGNP 2 using Huisgen [2+3] cycloaddition reaction}

Alkyne L3 $(55 \mathrm{mg})$ was added to silica coated NP $1(55 \mathrm{mg})$ suspended in dry toluene $(100 \mathrm{~mL})$ (Scheme S1a). The resulting mixture was sonicated for 12 hours and then stirred overnight. The resulting alkyne-functionalized NP S1 were magnetically 
isolated, washed with water, ethanol, diethyl ether, DMSO and redispersed in DMSO: $\mathrm{H}_{2} \mathrm{O}$ (4:1). 3-Azidopropyl $\alpha$-D-mannopyranoside $\mathbf{M 6}(55 \mathrm{mg}), \mathrm{CuSO}_{4} .5 \mathrm{H}_{2} \mathrm{O}(10 \mathrm{mg})$ and sodium ascorbate $(20 \mathrm{mg})$ were then added to NP $\mathbf{S} 1$ in DMSO: $\mathrm{H}_{2} \mathrm{O}(4: 1,50 \mathrm{~mL})$ under sonication. The reaction mixture was stirred at room temperature for 24 hours under nitrogen. The resulting MGNP 2 were then isolated and washed with water, ethanol and ether successively (Scheme S1b).

\section{Preparation of MGNPs 3 and 4 using amide (BOP) coupling:}

To prepare the amine functionalized NP S2, NP $\mathbf{1}$ was suspeneded in dry toluene $(150 \mathrm{~mL})$ and sonicated for 30 minutes. 3-Aminopropyltriethoxysilane (APTES $)^{7}(2 \%$ $\mathrm{w} / \mathrm{v}$ ) was then added and stirred at $60{ }^{\circ} \mathrm{C}$ overnight. The resulting amine functionalized NP S2 was isolated, washed and redispersed in ethanol. ${ }^{10}$ To immobilize the surface with sugar using amide bond coupling, NP S2 $(450 \mathrm{mg})$ was washed with DMF twice, redispersed in DMF $(150 \mathrm{~mL})$ and sonicated for 30 minutes. The coupling solution was prepared by mixing mannose amido-acid M5 $(0.515 \mathrm{~g})$, benzotriazole-1-yl-oxy-tris(dimethylamino)-phosphonium hexafluorophosphate (BOP) (1.1 g, 1.5 eq.), 1hydroxybenzotriazole (HOBT) (0.25 g, 1.3 eq.), and diisopropylethylamine (DIPEA) (1.0 $\mathrm{mL}, 4$ eq.) in DMF (15 mL). The coupling solution was then added dropwise to NP $\mathbf{S 2}$ in DMF under sonication. The reaction mixture was stirred overnight at room temperature. The resulting MGNP 3 was then isolated and washed with ether and ethanol. The same protocol was followed to synthesize the analogous Gal-MGNP 4 using galactose amidoacid G5 (Scheme S1c).

Scheme S1.

a)

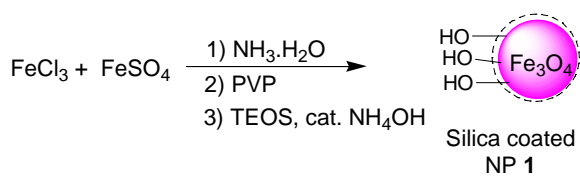

b)

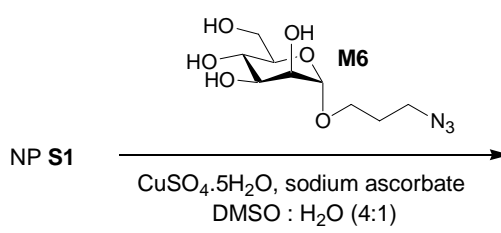

c)

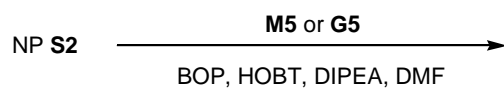

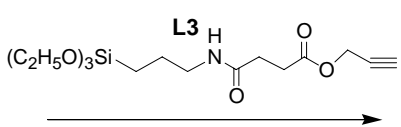

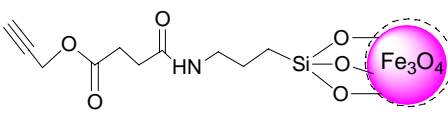

Alkyne functionalized NP S1
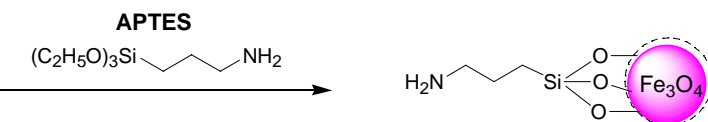

Amine functionalized NP S2
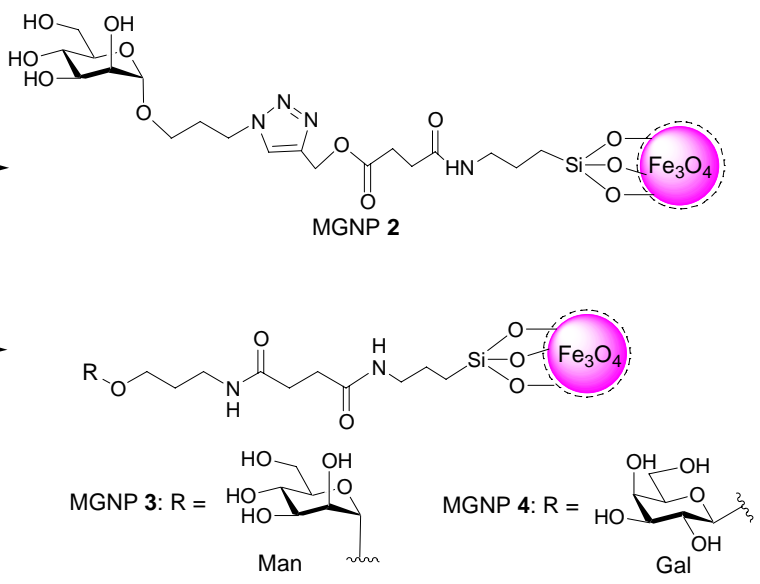


\section{Characterization of MGNPs}

Powder X-ray diffraction (XRD) was carried out to identify the nanocrystalline structure of our NPs in a dry powder form. The observed diffraction peaks coincide with the Jade database indicating that the NPs are magnetite $\left(\mathrm{Fe}_{3} \mathrm{O}_{4}\right)$.

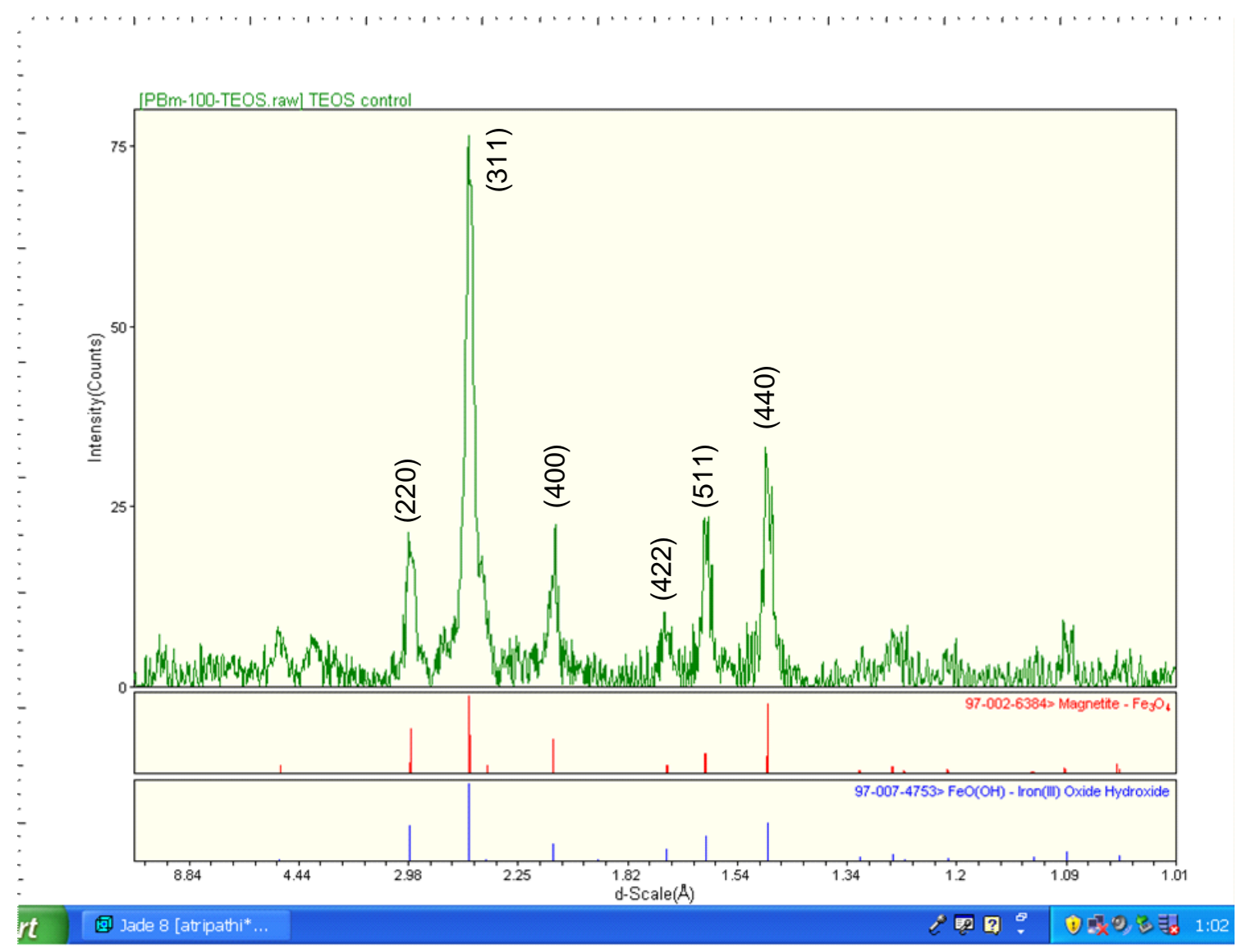

Figure S1. XRD of NP 1. 


\section{Fourier Transform Infrared Spectroscopy (FT-IR)}

FT-IR analysis was performed to characterize $\mathrm{Fe}_{3} \mathrm{O}_{4}$ magnetite nanoparticles as depicted in Figure S2. The fact that bare $\mathrm{Fe}_{3} \mathrm{O}_{4} \mathrm{NPs}$ were coated with TEOS was proven by comparing the IR spectra of coated and uncoated NPs. The IR spectrum of the bare NP shows two main bands at 577 and $453 \mathrm{~cm}^{-1}$ related to $\mathrm{Fe}-\mathrm{O}$ vibrations. Moreover, an intense and broad band appeared in the region 3200-3600 $\mathrm{cm}^{-1}$ region, corresponding to the $\mathrm{O}-\mathrm{H}$ stretching vibration. It can be seen that, compared with the bare NP, NP $\mathbf{1}$ possess additional absorption bands in the region 980-1220 $\mathrm{cm}^{-1}$ corresponding to

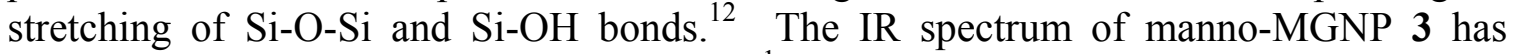
additional alkyl C-H stretching at $\sim 2900 \mathrm{~cm}^{-1}$.

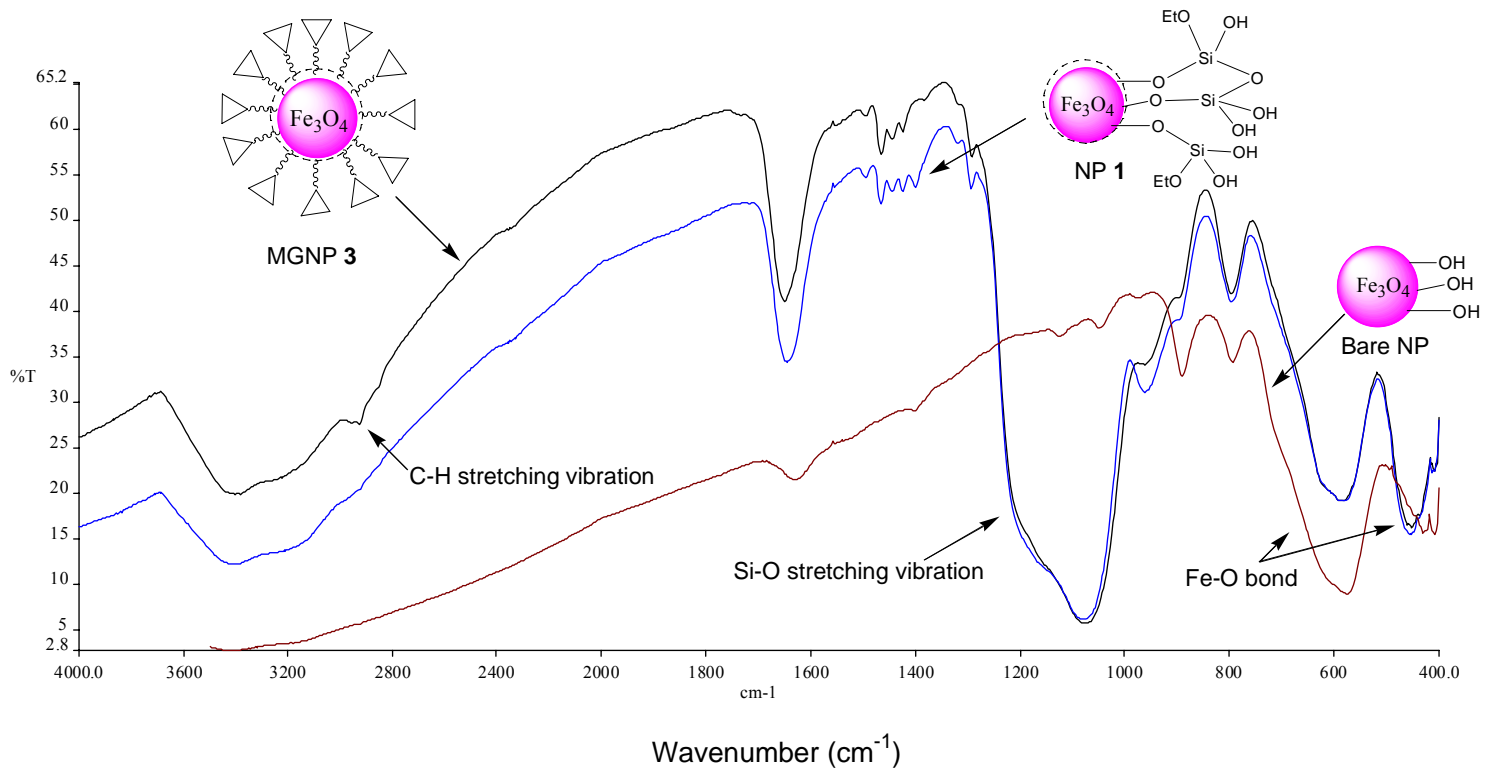

Figure S2. FT-IR spectra of bare iron oxide $\left(\mathrm{Fe}_{3} \mathrm{O}_{4}\right)$ NP (brown), NP 1 (blue) and MGNP 3 (black). 


\section{Thermogravimetric analysis (TGA):}

For thermogravimetric analysis (TGA) measurements, all nanoparticles were first heated to $100{ }^{\circ} \mathrm{C}$ and then cooled to $50{ }^{\circ} \mathrm{C}$ under dry nitrogen gas to remove all adsorbed water before any measurements were recorded. NP 1 exhibited a weight loss of $5.5 \%$, while the Man-MGNP 3 and Gal-MGNP 4 have weight loss of $13 \%$ and $11.5 \%$ respectively (Figure S3), implying the presence of organic molecules on the surface of MGNPs.

The number of mannose molecules on each MGNP 3 particle was estimated as the following:

The lattice volume of magnetite is $592 \AA^{3}$ and $Z=8$. The average diameter of MGNP is $10 \mathrm{~nm}$. Assuming the MGNP is a sphere, the number of lattices in one MGNP particle is 884 and the number of $\mathrm{Fe}_{3} \mathrm{O}_{4}$ (MW 232) molecule in each MGNP particle is 7072. From TGA, the weight of $\mathrm{Fe}_{3} \mathrm{O}_{4}$ accounts for $87 \%$ of the MGNP and $8 \%$ of the MGNP is due to the carbohydrates attached. Therefore, on average, there are 300 mannose molecules (M5 + APTES, MW 500) on each MGNP.

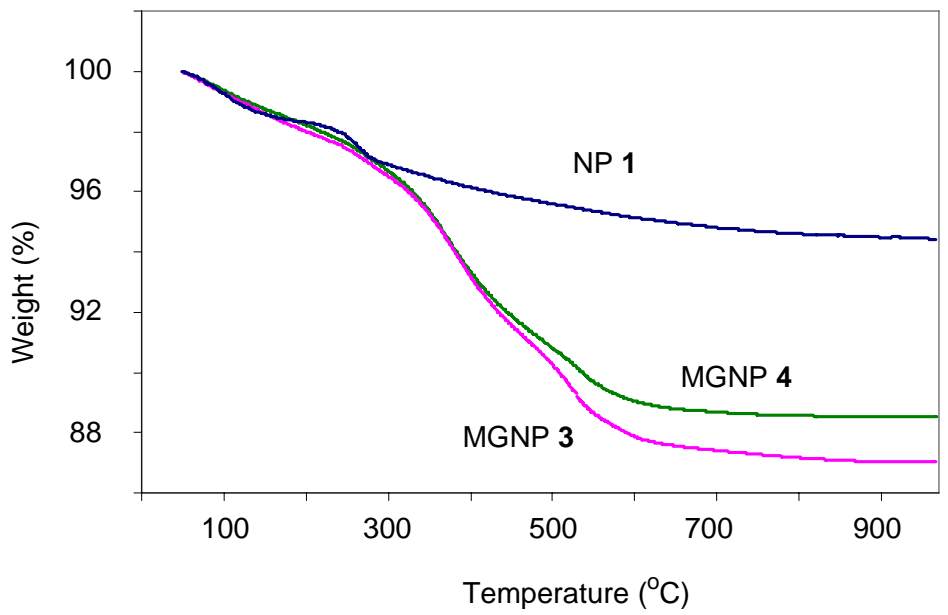

Figure S3. TGA curves for NP 1 (blue), Man-MGNP 3 (pink) and Gal-MGNP 4 (green). 


\section{Transmission electron microscopy (TEM):}

TEM images of MGNP 3 indicate the diameters of NPs are around $10 \mathrm{~nm}$ (Figure S4). Samples were prepared by depositing $5 \mu \mathrm{l}$ of the particle dispersion onto 200 mesh carbon-coated copper grids with a pipet. The suspension was then allowed to settle for 1 to $2 \mathrm{~min}$ before excess liquid was removed with a paper wick. A drop of $1 \%$ phosphotungustic acid was then used to negatively stain MGNP/E. coli aggregates for 1 minute. ${ }^{13}$

a)
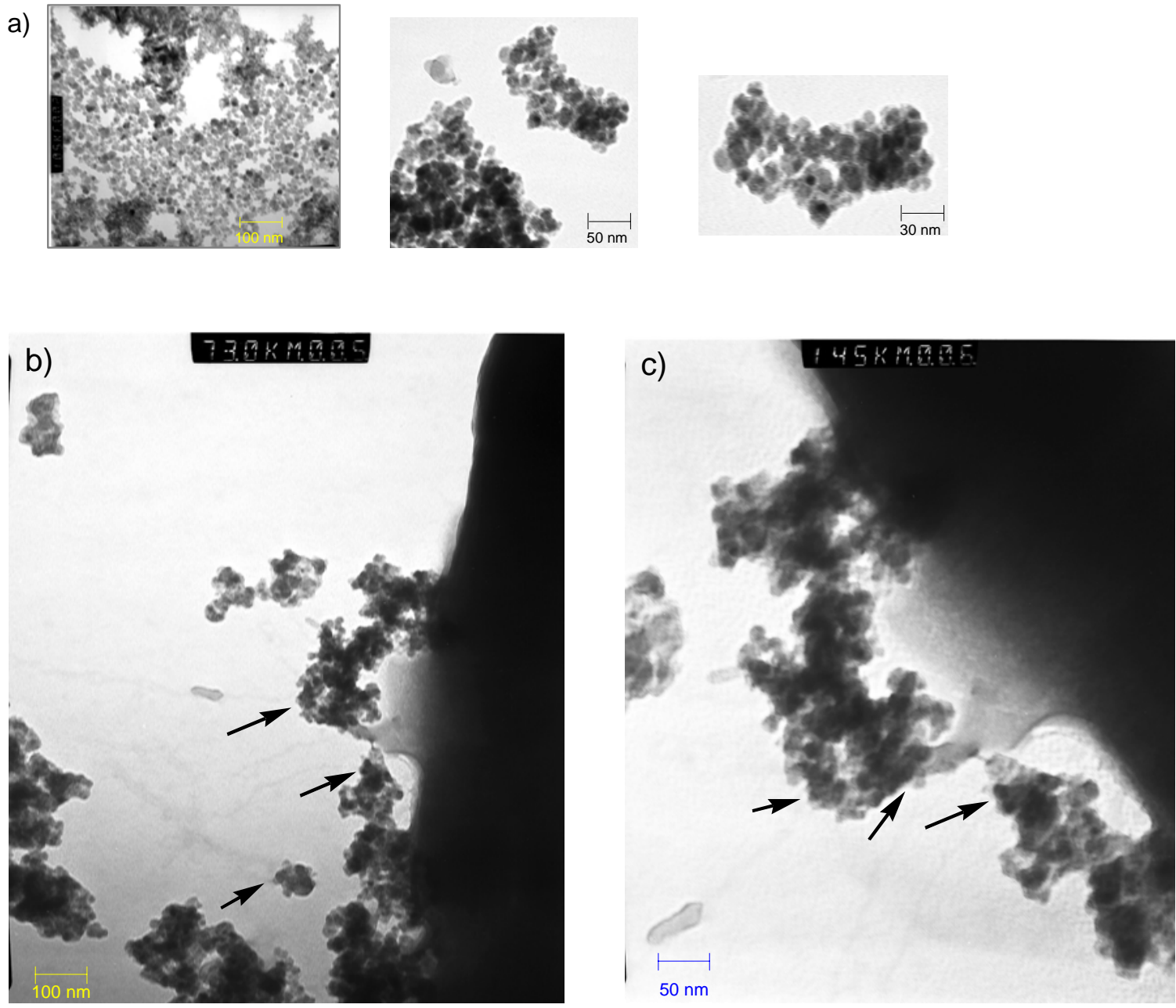

Figure S4. TEM images of a) MGNP 3 at different magnifications. b), c) MGNP 3 /E. coli aggregates. Arrows indicate where MGNP 3 binds to the pili, which were faintly stained in the pictures. 


\section{4- Con A studies:}

Fluorescein-labeled Con A (4 mg) was dissolved in $0.1 \mathrm{M} \mathrm{NaHCO}_{3}$ solution (40 $\mathrm{mL})$ to obtain Con A $(100 \mu \mathrm{g} / \mathrm{mL})$ solution. Incubations of fluorescein-labeled Con A with same amounts (5 mg) of MGNP 2, MGNP 3 or NP 1 were carried out at $4{ }^{\circ} \mathrm{C}$ for 12 hours (Scheme S2). A magnetic field was applied to the mixture through a handheld magnet inducing aggregation of magnetic NPs on the side of the cell. The supernatant was carefully removed by pipetting and the residual fluorescence of supernatants was then recorded with an excitation wavelength at $492 \mathrm{~nm}$ and emission scan from 500-650 nm (Figure S5).

Scheme S2. Schematic representation of MGNP-Con A interactions.
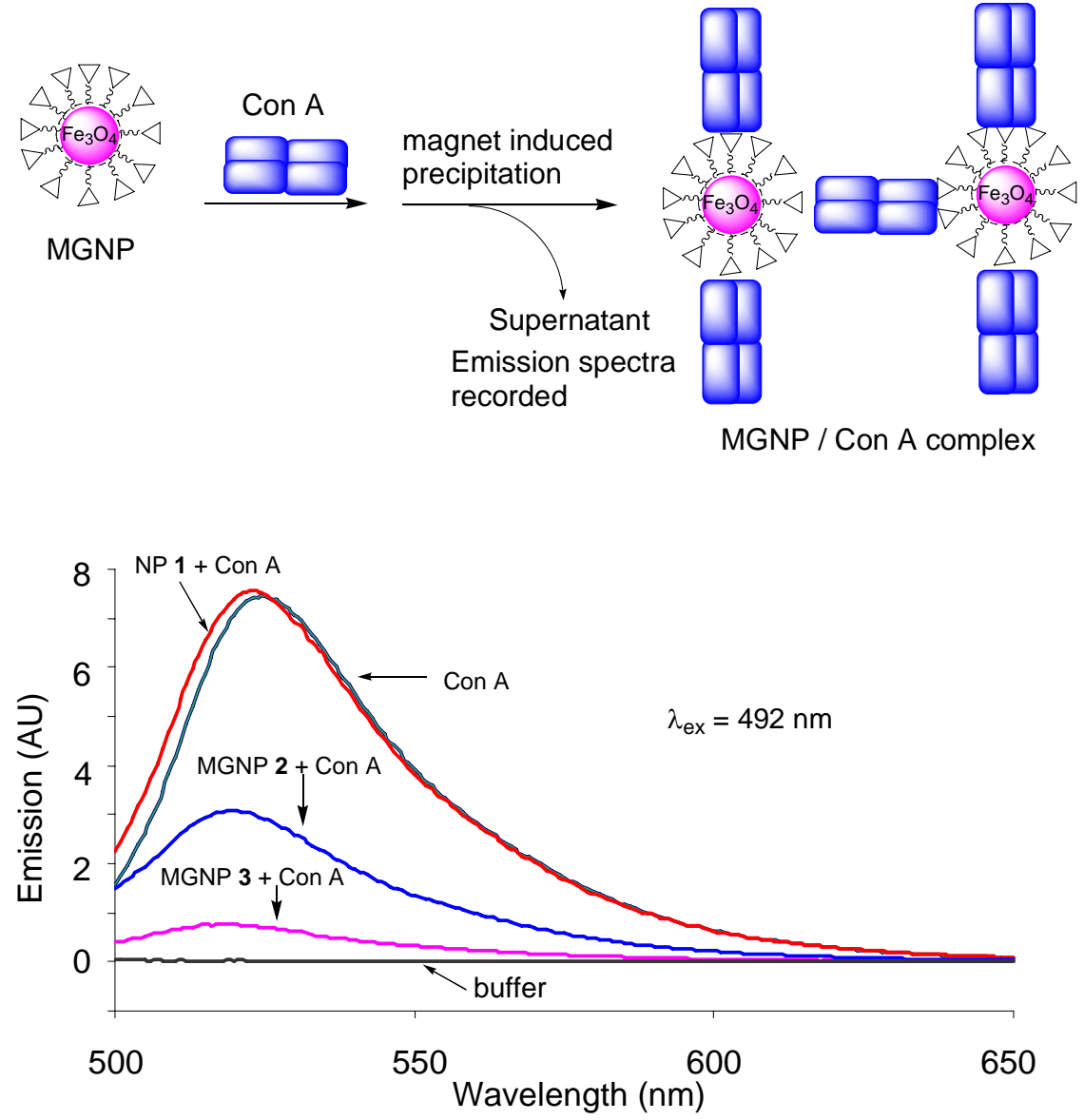

Figure S5. Fluorescent emission spectra of the supernatants of fluorescein labeled Con A solutions after incubation with NPs and subsequent magnet mediated separation.

To test the separation efficiency dependence on concentration, different amounts of MGNP $3(0.2 \mathrm{mg}, 1 \mathrm{mg}, 2 \mathrm{mg}, 5 \mathrm{mg})$ were mixed with fluorescein labeled Con A (100 $\mu \mathrm{g} / \mathrm{mL}, 2 \mathrm{~mL}$ ) at $4{ }^{\circ} \mathrm{C}$ for 12 hours. The particles were then subjected to magnetic separation and the fluorescence spectra of the supernatant were recorded. It was observed that with increasing the concentration of MGNP 3, the amount of Con A removed by MGNP 3 increased, resulting in decreased fluorescence emission intensity (Figure S6). 


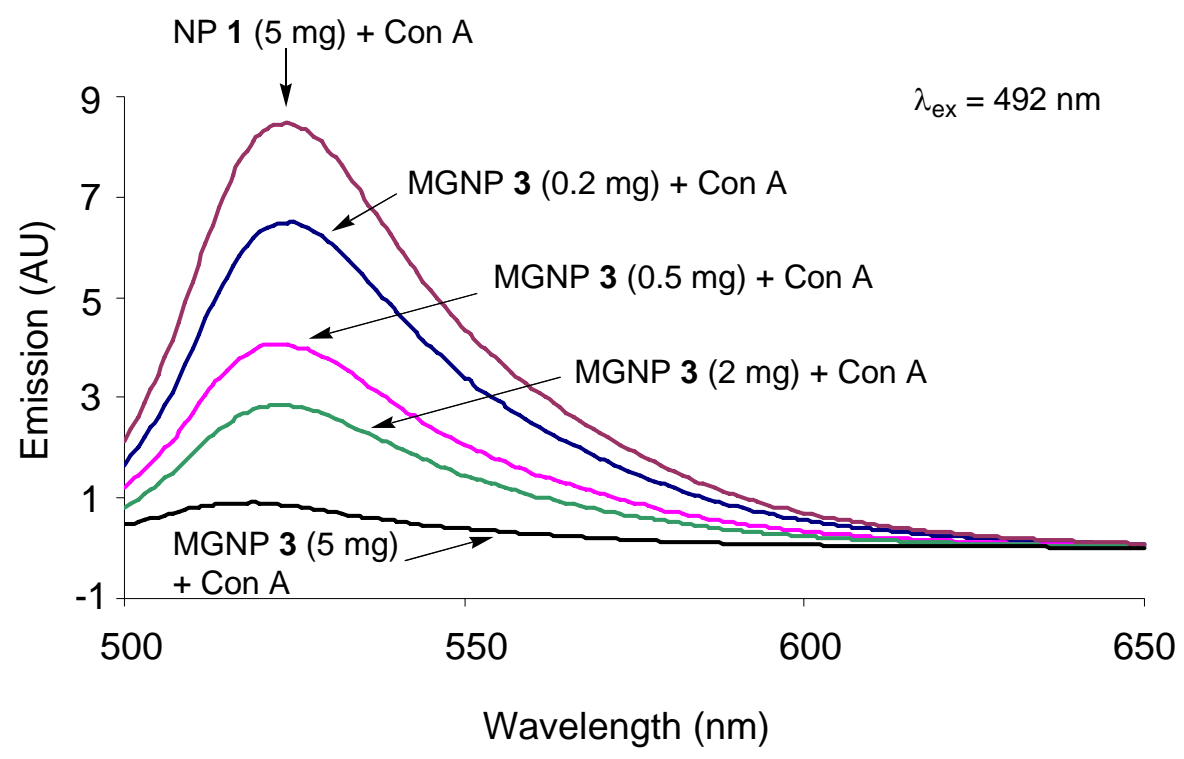

Figure S6. Fluorescence emission spectra of the supernatants of fluorescein labeled Con A solutions after incubation with NP 1 ( $5 \mathrm{mg}$ ) and various amounts of MGNP 3 followed by magnetic separation. 


\section{5- E. coli detection:}

\section{Incubation of MGNP with $E$. coli Cells.}

E. coli cells were grown overnight in $\mathrm{LB}$ media at $37^{\circ} \mathrm{C}$ to an approximately $10^{9}$ cells/mL. The culture was then centrifuged and cells washed with Phosphate Buffered Saline (PBS) buffer. PBS was prepared following a known protocol. PBS involves making up two stock solutions:

- Monobasic sodium phosphate $\mathrm{NaH}_{2} \mathrm{PO}_{4}$ (0.2 M Solution): $27.6 \mathrm{~g} /$ liter of DDW

- Dibasic sodium phosphate $\left(\mathrm{Na}_{2} \mathrm{HPO}_{4}\right)$ (0.2 M Solution): $28.4 \mathrm{~g} /$ liter of DDW

Then, for one liter of PBS, $280 \mathrm{~mL}$ monobasic stock was mixed with $720 \mathrm{~mL}$ dibasic stock and then $9 \mathrm{~g}$ of $\mathrm{NaCl}$ was added.

MGNPs were added to a $4 \mathrm{ml}$ vial containing E. coli solution $\left(10^{3}-10^{7}\right.$ cells $/ \mathrm{mL}, 1$ $\mathrm{mL}$ ) in PBS buffer, mixed well, and incubated at room temperature with gentle shaking. After incubation, the samples were left on a permanent external magnet for 1 minute. The supernatant was carefully removed by pipetting and the resulting nanoparticles were washed three times and then re-suspended with PBS to the original volume. It is worth mentioning that the successive buffer washing cycles are crucial to remove unbound cells and hence nonspecific binding. All samples were then fixed with $37 \%$ paraformaldehyde $(54 \mu \mathrm{L} / \mathrm{mL})$, sonicated for 2 minutes and then stained with PicoGreen (2 $\mu \mathrm{L} / \mathrm{mL}$ sample) a fluorescent non-specific nucleic acid stain for 5 minutes. Since aggregation of bacterial cells interferes with accurate optical quantification, the cells were dispersed by sonication (Virsonic 50, Virtis, Gardiner, NY). E. coli detection and enumeration was carried out using epifluorescent microscopy. Samples were vacuumfiltered through a glass fiber prefilter and black polycarbonate filter (25-mm diameter; $0.22 \mu \mathrm{m})$. The filter paper was then air dried, transferred to a microscope slide, covered with a drop of immersion oil and a cover glass, and imaged. Individual cells were quantified by counting randomly at least 20 fields per each run and a minimum of 200 cells. The total number of cells on each slide was calculated by multiplying the average number of cell per field by the number of fields (46691 at 1000X magnification) per slide. The minimum detection level using this method is $10^{4}$ cells, which corresponds to 1 cell per field on average. All measurements were reproducible and the deviations were found to be within $10 \%$.

\section{Evaluation of Capture Efficiency Variation}

Four solutions of $E$. coli cells $\left(\sim 1.5 \times 10^{6}\right.$ cell $\left./ \mathrm{mL}, 1 \mathrm{~mL}\right)$ were incubated with MGNP 3 (2 mg) each for 45 minutes and the capture efficiency (C. E.) for each incubation was calculated (Table S1 and Figure S7). The average capture efficiency for this quadruplicate experiment is $83.5 \pm 3.4 \%$.

Table S1. Capture efficiencies of E. coli ORN $178\left(\sim 1.5 \times 10^{6}\right.$ cell $\left./ \mathrm{mL}\right)$ by MGNP $3(2 \mathrm{mg})$

\begin{tabular}{cccc} 
Entry \# & $\begin{array}{c}\text { \# of Cells in Supernatant } \\
\left(10^{6} \text { cells } / \mathrm{mL}\right)\end{array}$ & $\begin{array}{c}\text { \# of Cells in MGNP 3 aggregate } \\
\left(10^{6} \text { cells } / \mathrm{mL}\right)\end{array}$ & C. E. (\%) \\
& 0.23 & 1.17 & 84 \\
2 & 0.23 & 0.93 & 80 \\
\hline
\end{tabular}




\begin{tabular}{llll}
\hline 3 & 0.12 & 0.96 & 88 \\
4 & 0.29 & 1.33 & 82 \\
\hline
\end{tabular}

Capture Efficiency (C.E.) $=\frac{\# \text { of cells in MGNP aggregate }}{\# \text { of cells in MGNP aggregate }+ \text { \# of cells in supernatant }}$

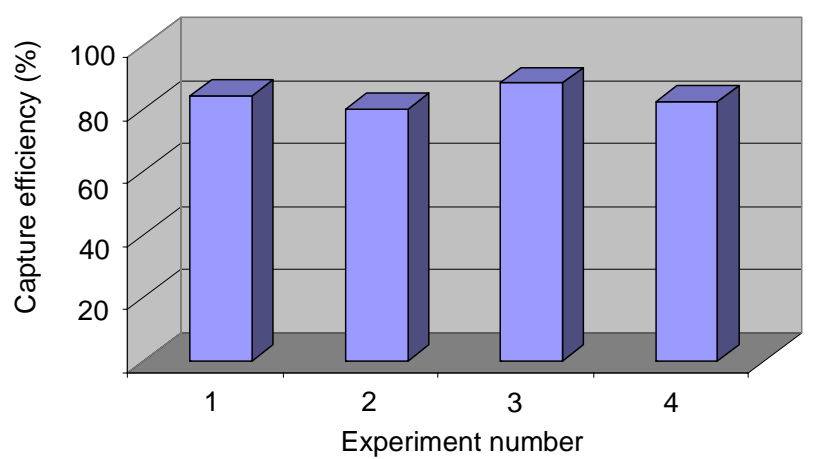

Figure S7. Capture efficiencies of E. coli ORN $178\left(\sim 1.5 \times 10^{6}\right.$ cell/mL $)$ by MGNP $3(2 \mathrm{mg})$

\section{Effect of Incubation Time on C. E.}

E. coli cells $\left(10^{6}\right.$ cell $\left./ \mathrm{mL}, 1 \mathrm{~mL}\right)$ were incubated with MGNP 3 (2 mg) for different time period $(5,15,30$ and 45 minutes) and C. E. for each incubation was calculated (Table S2 and Figure S8).

Table S2

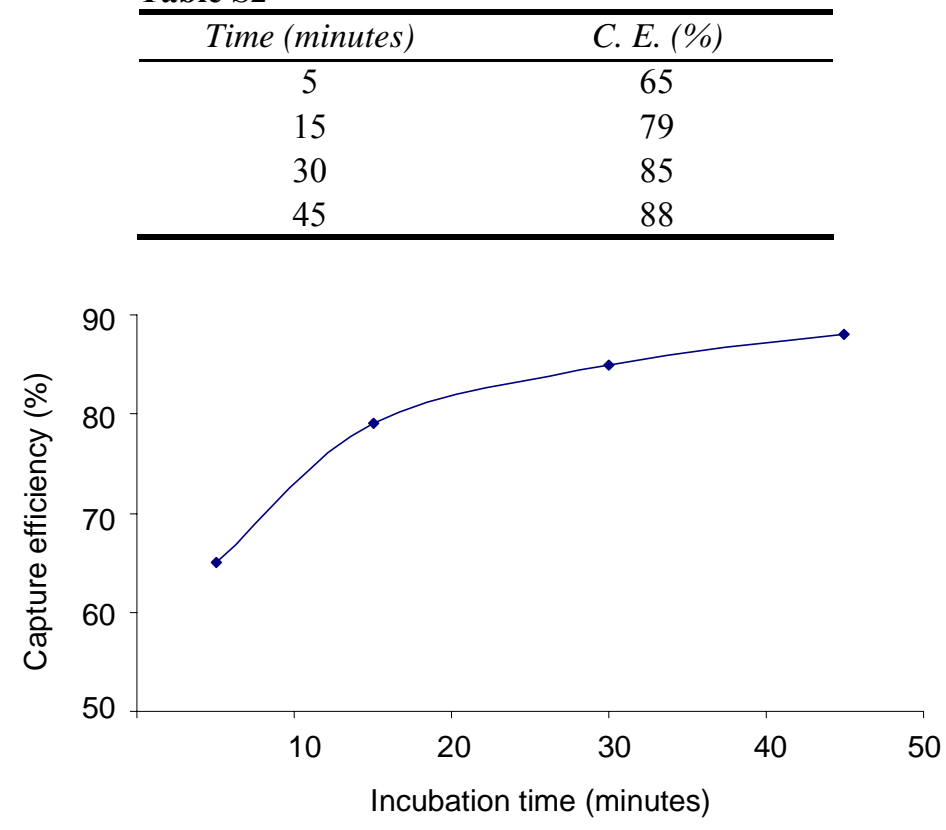

Figure S8. 


\section{Strain Differentiation:}

Table S3. Responses of MGNPs 3 and 4 to E. coli ORN 178, ORN 208, and ES.

\begin{tabular}{lccc}
\hline & $\begin{array}{c}\text { \# of Cells in Supernatant } \\
\left(10^{6} \text { cells } / \mathrm{mL}\right)\end{array}$ & $\begin{array}{c}\text { \# of Cells in MGNP aggregate } \\
\left(10^{6} \text { cells / } \mathrm{mL}\right)\end{array}$ & $\begin{array}{c}\text { C. E. (\%) } \\
\text { MGNP 3 / ORN178 }\end{array}$ \\
MGNP 4 / ORN178 & 1.00 & 1.85 & 65 \\
MGNP 3 / ORN208 & 1.72 & 0.30 & 15 \\
MGNP 4 / ORN208 & 2.66 & 0.16 & 6 \\
MGNP 3 / ES & 2.58 & 0.40 & 13 \\
MGNP 4/ ES & 1.61 & 3.74 & 70 \\
\hline
\end{tabular}




\section{6- Selected NMR spectra}

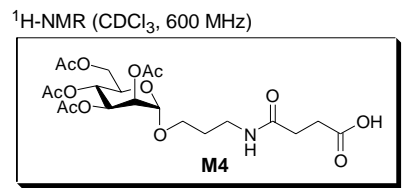
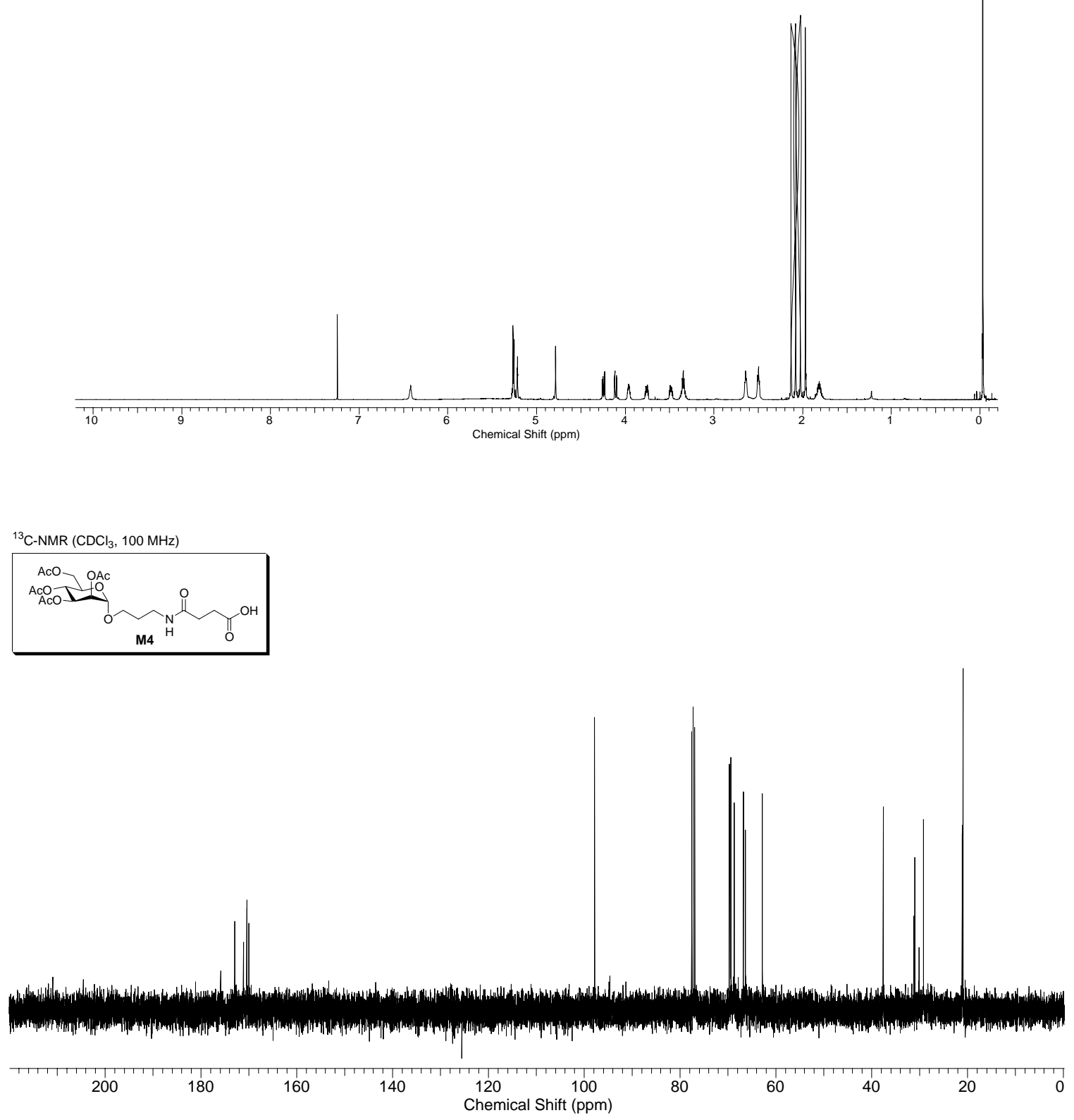

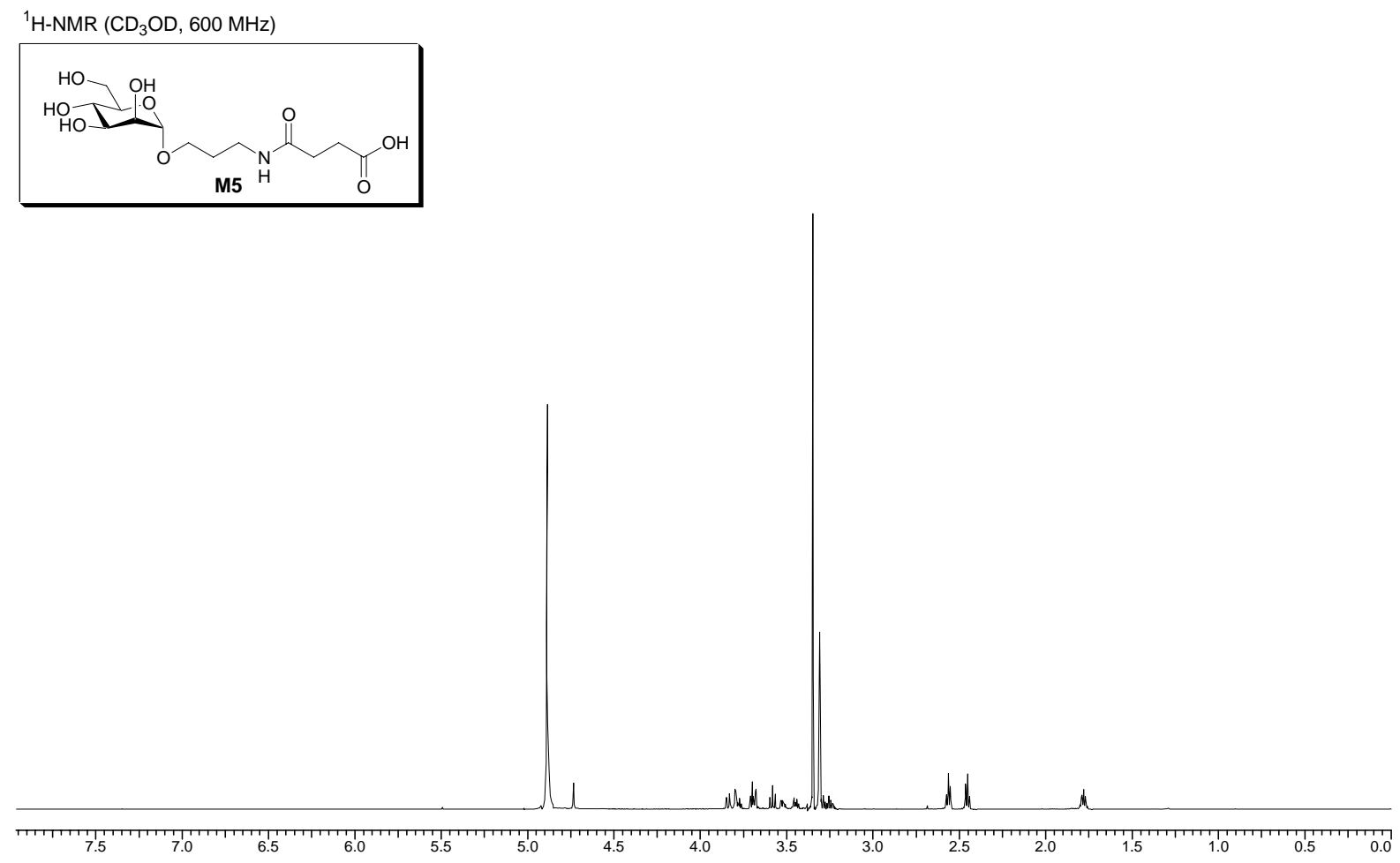

${ }^{13} \mathrm{C}-\mathrm{NMR}\left(\mathrm{CD}_{3} \mathrm{OD}, 100 \mathrm{MHz}\right)$

(n)



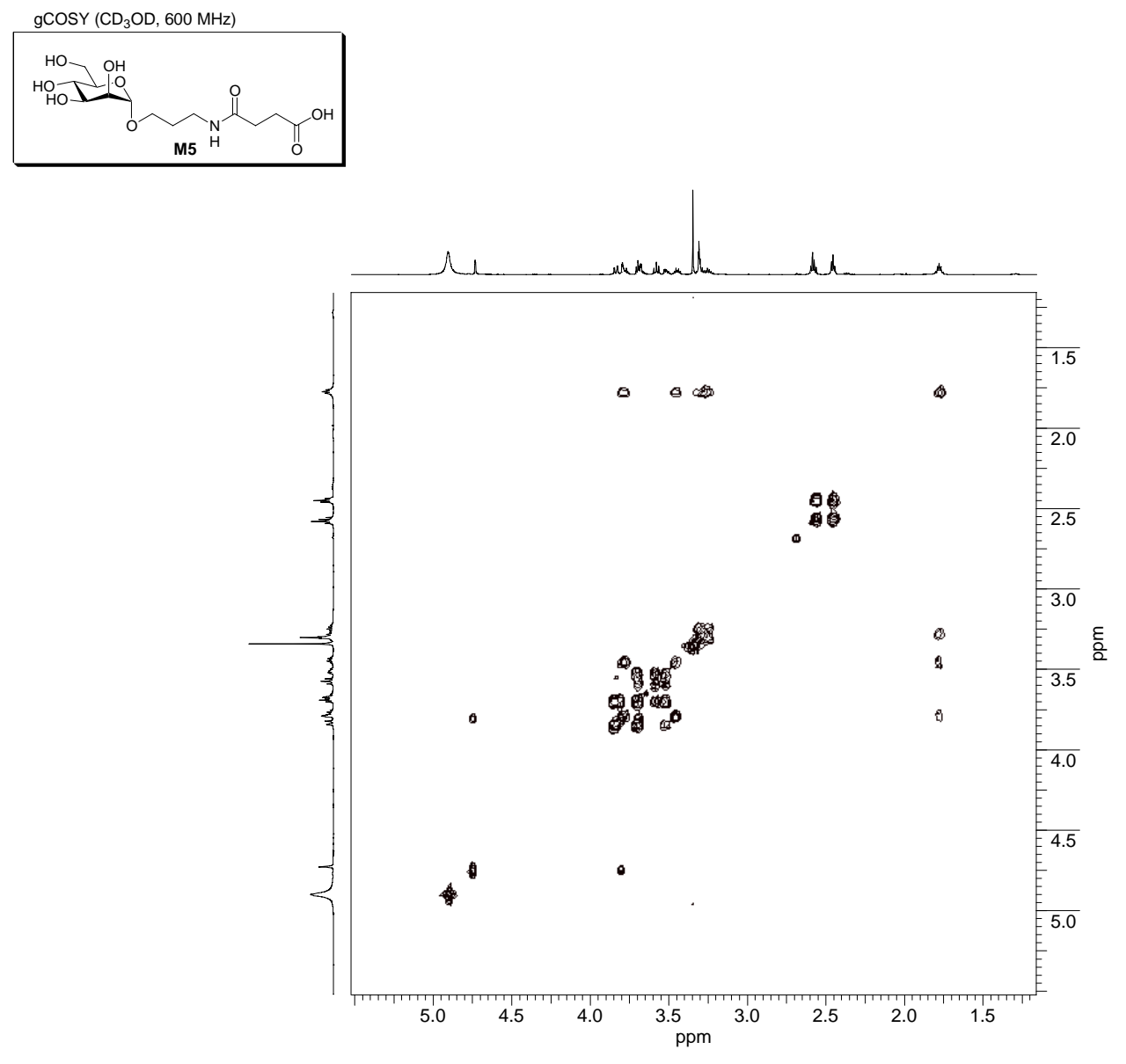

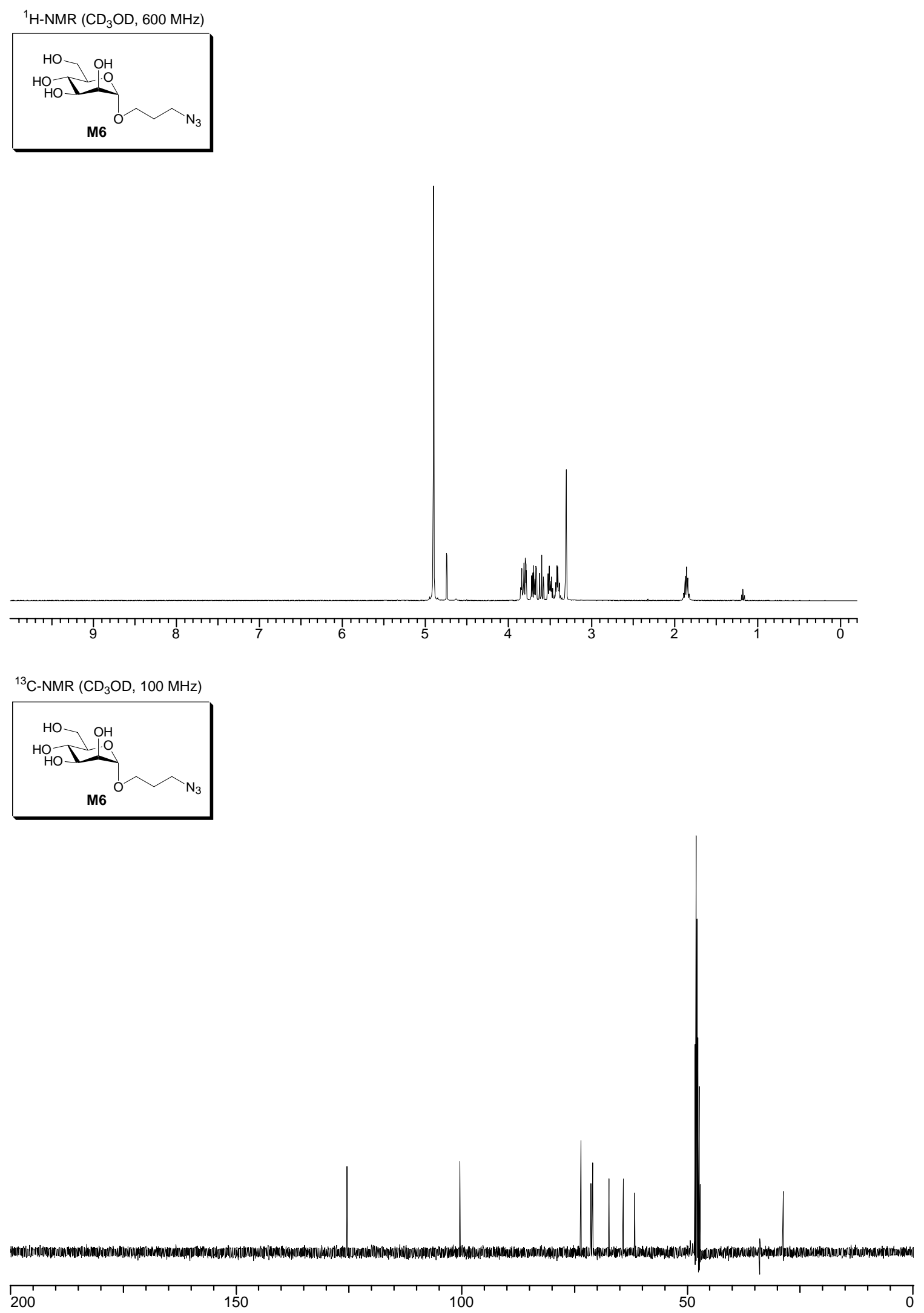
${ }^{1} \mathrm{H}-\mathrm{NMR}\left(\mathrm{CDCl}_{3}, 600 \mathrm{MHz}\right)$

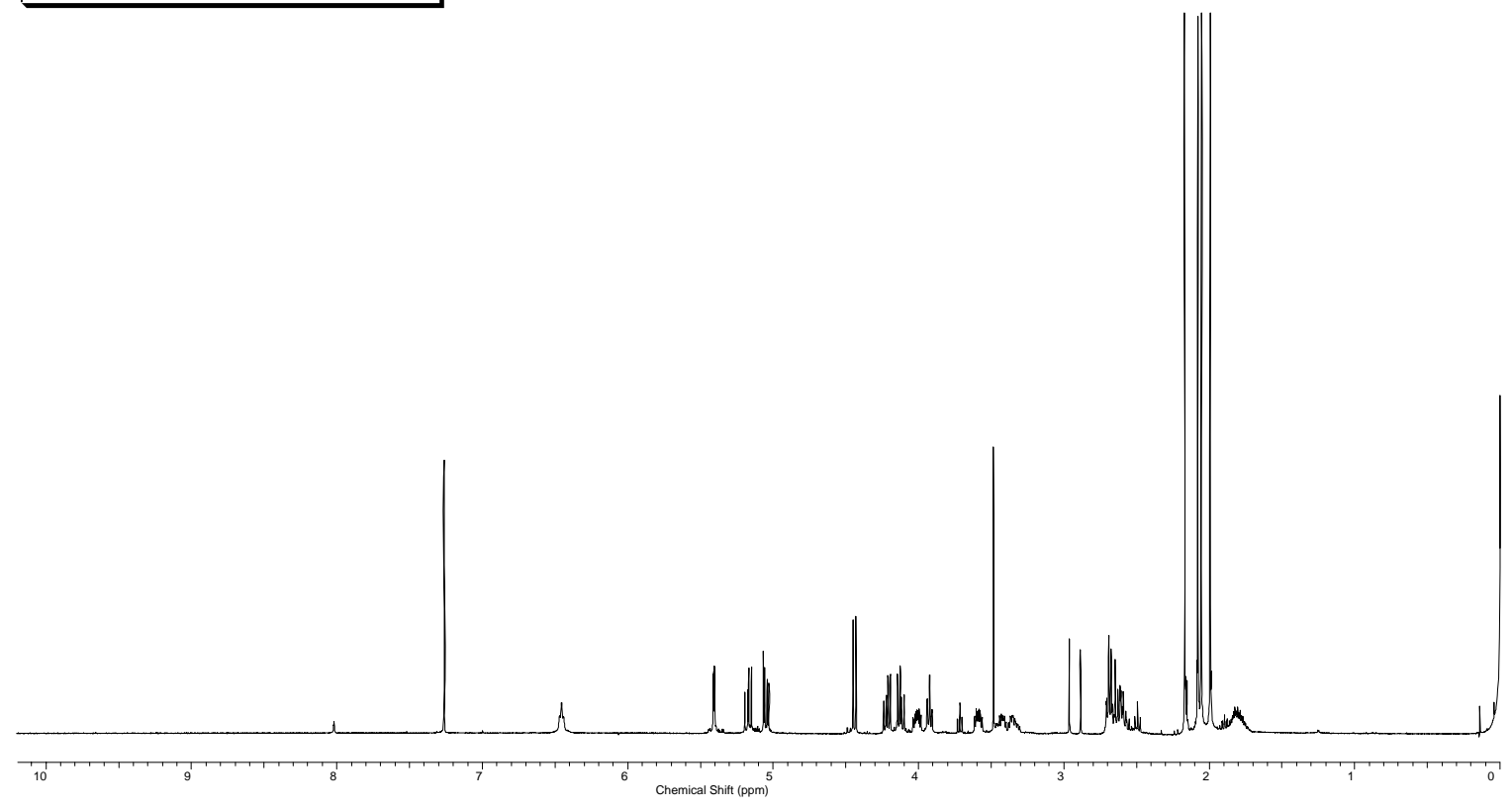

${ }^{13} \mathrm{C}-\mathrm{NMR}\left(\mathrm{CDCl}_{3}, 100 \mathrm{MHz}\right)$

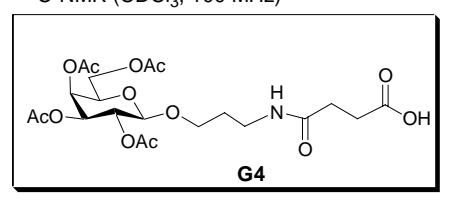



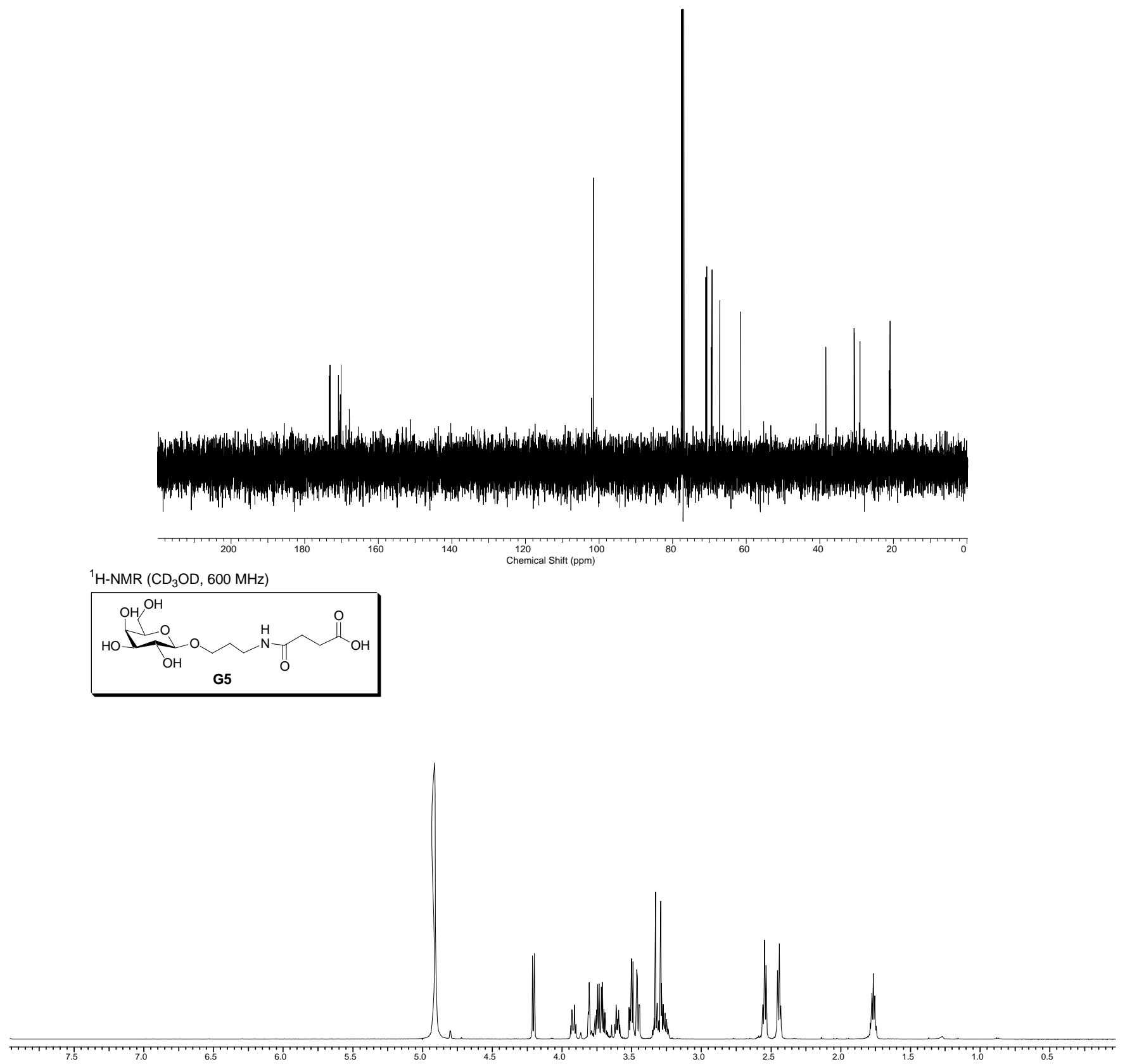

${ }^{13} \mathrm{C}-\mathrm{NMR}\left(\mathrm{CD}_{3} \mathrm{OD}, 100 \mathrm{MHz}\right)$

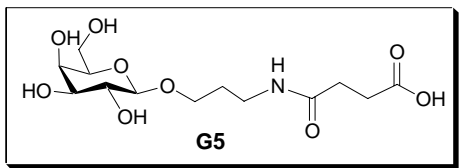




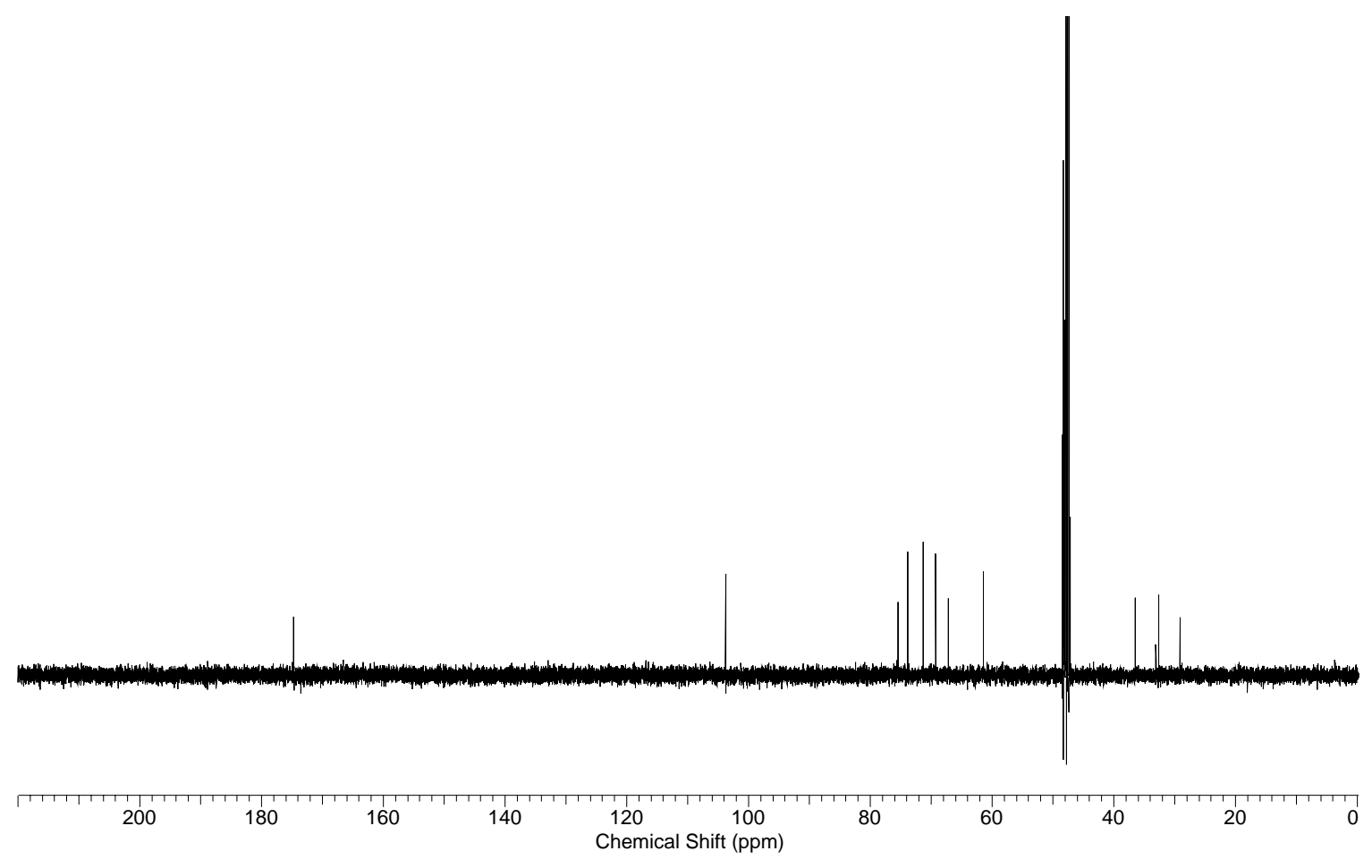



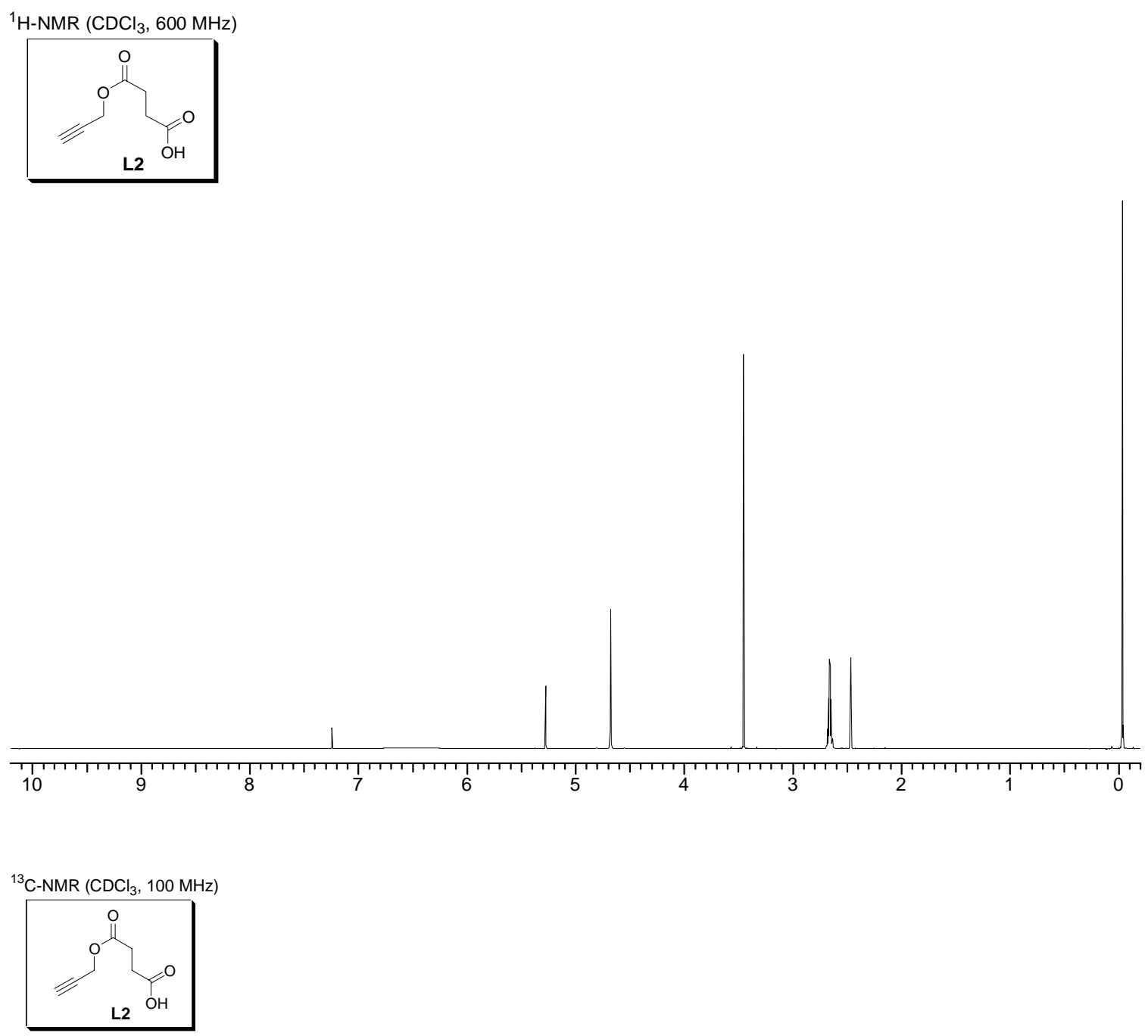

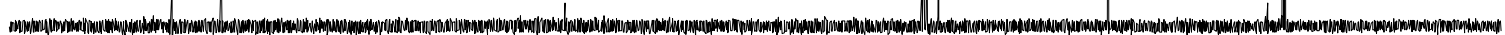

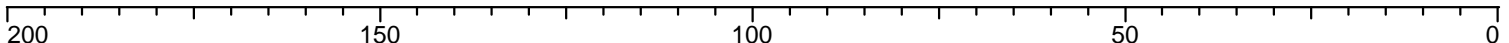


${ }^{1} \mathrm{H}-\mathrm{NMR}\left(\mathrm{CDCl}_{3}, 600 \mathrm{MHz}\right)$
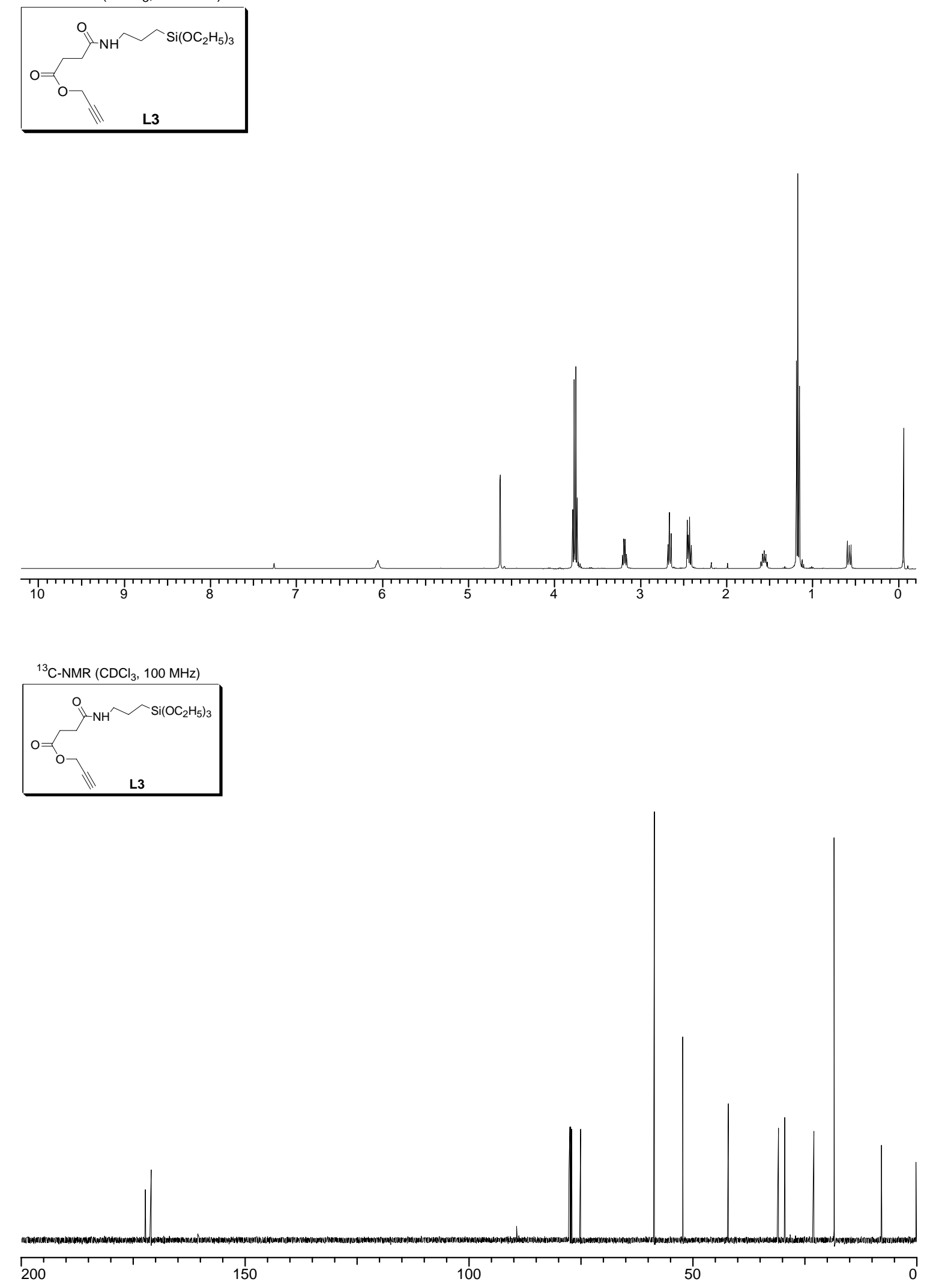


\section{7- References:}

(1) Hayes, W.; Osborn, H. M. I.; Osborne, S. D.; Rastall, R. A.; Romagnoli, B. Tetrahedron 2003, 59, 7983-7996.

(2) Davis, B. G.; Wood, S. D.; Maughan, M. A. T. Can. J. Chem. 2002, 80, 555-558.

(3) Ladmiral, V.; Mantovani, G.; Clarkson, G. J.; Cauet, S.; Irwin, J. L.; Haddleton, D. M. J. Am. Chem. Soc. 2006, 128, $4823-4830$.

(4) Joosten, J. A. F.; Loimaranta, V.; Appeldoorn, C. C. M.; Haataja, S.; El Maate, F. A.; Liskamp, R. M. J.; Finne, J.; Pieters, R. J. J. Med. Chem. 2004, 47, 6499-6508.

(5) Cheng, F. Y.; Su, C. H.; Yang, Y. S.; Yeh, C. S.; Tsai, C. Y.; Wu, C. L.; Wu, M. T.; Shieh, D. B. Biomaterials 2005, 26, 729-738.

(6) Srinivasan, B.; Huang, X. Chirality, 2007, 19, in press.

(7) Ma, M.; Zhang, Y.; Yu, W.; Shen, H.; Zhang, H.; Gu, N. Coll. Sur. A 2003, 212, 219-226.

(8) Yoon, T. J.; Kim, J. S.; Kim, B. G.; Yu, K. N.; Cho, M. H.; Lee, J. K. Angew. Chem. Int. Ed. 2005, 44, 1068 -1071.

(9) Lu, Y.; Yin, Y.; Mayers, B. T.; Xia, Y. Nano Lett. 2002, 2, 183-186.

(10) Bruce, I. J.; Sen, T. Langmuir 2005, 21, 7029-7035.

(11) Liu, X.; Ma, Z.; Xing, J.; Liu H. J. Magn. Mag. Mater. 2004, 270, 1-6.

(12) Klotz, M.; Ayral, A.; Guizard, C.; Menager,C.; Cabuil, V. J. Coll. Inter. Sci. 1999, $220,357-361$.

(13) Lin, C. C.; Yeh, Y. C.; Yang, C. Y.; Chen, C. L.; Chen, C. F.; Chen, C. C.; Wu, Y. C. J. Am. Chem. Soc. 2002, 124, 3508-3509. 